\title{
Role of the Midbrain Periaqueductal Gray in Maternal Nurturance and Aggression: c-fos and Electrolytic Lesion Studies in Lactating Rats
}

\author{
Joseph S. Lonstein and Judith M. Stern \\ Department of Psychology, Rutgers, The State University of New Jersey, New Brunswick, New Jersey 08903
}

The upright crouched, or kyphotic, nursing posture of lactating rats is dependent on suckling stimulation from pups. Because of the neuroanatomical connections of the periaqueductal gray (PAG) and its sensorimotor integration of the analogous lordosis posture displayed by sexually receptive female rats, the possible role of the PAG in kyphosis was investigated using $c$-fos immunocytochemistry and electrolytic lesions. Lactating rats interacting with and nursing a litter of suckling pups showed greater Fos-immunoreactive nuclei in the lateral and ventrolateral caudal PAG $\left(\mathrm{cPAG}_{\mathrm{I}, \mathrm{v}}\right)$ compared with dams receiving nonsuckling somatosensory, distal, or no stimulation from pups. In contrast, this pattern was not evident in the rostral PAG, where the highest Fos levels occurred in nonsuckled dams, or in five other brainstem sites with either no group differences (peripeduncular, dorsal raphe, and pontine nuclei) or negligible Fos (ventral tegmental area, spinal trigeminal nuclei). After bilateral electrolytic lesions of the $\mathrm{CPAG}_{1, \mathrm{vl}}$ during gestation or on day 7 postpartum, active maternal behaviors, such as retrieval and licking of pups, and total nursing time were essentially normal. Kyphotic nursing, however, was reduced by $85 \%$, nursing in prone and supine postures increased substantially, and $24 \mathrm{hr}$ litter weight gains were reduced, particularly early in lactation (by 26\%). Furthermore, lesioned rats attacked a strange male twice as often as controls did, which is suggestive of reduced fearfulness. These results extend the known roles of the PAG in reproductive and defensive behaviors to the postural control of suckling-induced kyphotic nursing and the modulation of maternal aggression.

Key words: nursing behavior; maternal aggression; c-fos; suckling; lactation; rostral PAG; caudal PAG
The periaqueductal gray (PAG) is involved in many functions, including vocalization (Waldbillig, 1975; Holstege, 1989), analgesia (Basbaum and Fields, 1984), defense (Bandler and Depaulis, 1991), responses to fear (Fanselow, 1991), and sexual receptivity (Sakuma and Pfaff, 1979a,b; Hennessey et al., 1990). Because of the numerous similarities between the sensorimotor characteristics of female sexual and maternal behaviors (Stern, 1990, 1996a), we investigated the possible role of the PAG in maternal behavior.

Sexual behavior of female rats consists of motorically active solicitation behaviors and lordosis, the immobile reflexive posture of receptivity, which is elicited by dorsolateral flank and perivaginal somatosensory stimulation that is carried to the brainstem via the ventrolateral funiculi and integrated in the PAG (Pfaff and Modianos, 1985; Pfaff et al., 1994). Analogously, maternal behavior consists of motorically active behaviors, such as retrieval and licking of pups, followed by quiescent nursing postures. The most characteristic nursing posture, especially in early lactation (Stern and Levine, 1972), is the reflexive upright crouch, recently termed "kyphosis" (Stern, 1996a), which is elicited by ventral trunk stimulation, principally suckling (Stern and Johnson, 1990; Stern et al., 1992; Stern, 1996a), that is carried supraspinally via the dorsolat-

Received Jan. 3, 1997; accepted Jan. 27, 1997.

This research was supported by National Institute of Mental Health Grant MH40459 (J.M.S.) and a Busch Biomedical Research Grant of Rutgers University (J.M.S., J.M. Swann). We thank Dr. Jennifer M. Swann and her laboratory assistants for their help in demonstrating the Fos immunocytochemistry procedures, Dr. Pauline Yahr and Ms. Michaela Heeb for their suggestions on Fos quantification, Ms. Danielle Simmons for assistance with behavioral observations, and Drs. M David Egger and David Crockett and Ms. Sue Harris for help with the photomicrographs.

Correspondence should be addressed to Dr. Judith M. Stern, Department of Psychology, Rutgers University, New Brunswick, NJ 08903.

Copyright (C) 1997 Society for Neuroscience $0270-6474 / 97 / 173364-15 \$ 05.00 / 0$ eral funiculi (Stern et al., 1993). Lordosis and kyphosis are characterized by bilateral symmetry, rigid leg support, and dorsi- and ventriflexion of the spinal column, respectively. On the basis of these analogies between lordosis and kyphosis, the neurophysiological responsiveness of the PAG to somatosensory inputs (Yezierski, 1991), strong reciprocal innervation between the PAG and the spinal cord (Mantyh and Pechanski, 1982; Mouton and Holstege, 1994), and extensive projections of the PAG to premotor areas of the gigantocellularis and paragigantocellularis nuclei of the rostral medulla (Van Bockstaele et al., 1991; Cameron et al., 1995), we conjectured that the PAG provides the sensorimotor integration of kyphosis.

To elucidate the possible role of the PAG in SK-induced kyphotic nursing, we used a functional marker of increased neuronal stimulation, activity of the immediate-early gene $c$-fos (Morgan and Curran, 1991). We found that in lactating rats there was maximal expression of Fos protein in the lateral and ventrolateral regions of the caudal PAG $\left(\mathrm{cPAG}_{1, \mathrm{vl}}\right)$ in response to interaction with suckling pups compared with nonsuckling or inaccessible pups or no stimulation from pups. This pattern of Fos expression was site-specific, being found in no other brainstem regions. Furthermore, we studied the effects on maternal behavior of electrolytic lesions of the $\mathrm{CPAG}_{1, \mathrm{vl}}$. To distinguish between the hormonal onset and nonhormonal maintenance of these behaviors (Bridges, 1996), lesions were performed both prepartum and postpartum. Finally, because the PAG is also involved with defensive behavior (Bandler and Depaulis, 1991) and behavioral responses to fear (Fanselow, 1991), both of which have been associated with maternal aggression in rats (Fleming and Luebke, 1981; Hård and Hansen, 1985; Hansen and Ferreira, 1986a,b; Lucion and de Almeida, 1996), we assessed behavior of dams 
toward a strange male intruder. Dams with $\mathrm{cPAG}_{1, \mathrm{vl}}$ lesions showed a specific and severe impairment in kyphosis and heightened maternal aggression.

\section{MATERIALS AND METHODS}

Animals and housing. All methods received the prior approval of the Animal Care Committee of Rutgers University. Subjects were primiparous Long-Evans rats (Rattus norvegicus), and their litters were born and raised in our colony, as detailed by Stern and Lonstein (1996). Additional animals used were lactating dams from our colony, of the same postpartum stage as experimental dams, that were used as surrogates, and sexually inexperienced 50- to 75-d-old Long-Evans males from our colony that were used in tests of maternal aggression. In most cases, males were used only once and killed immediately after testing; in a few cases, however, males that were not injured were used once again in a subsequent maternal aggression test with at least 1 week intervening. Lights were on for $12 \mathrm{hr} / \mathrm{d}$, beginning at 8 A.M., food and water were freely available, the room temperature was $22 \pm 1^{\circ} \mathrm{C}$, and the humidity was $40-50 \%$; wood shavings were used for bedding. Each pregnant rat was rehoused individually at least $4 \mathrm{~d}$ before parturition: in the Fos study, in an opaque, polypropylene pan cage $(48 \times 28 \times 16 \mathrm{~cm})$, and in the lesion studies, in a glass terrarium $(64 \times 30 \times 30 \mathrm{~cm})$ continually provided with a shredded paper towel in addition to bedding material and fitted with a half-black Plexiglas cover that resulted in the nest being built under the darkened half of the cage. All day designations refer to time since parturition. Litters were culled to eight pups by day 1 . During 3 or $4 \mathrm{hr}$ separations from their dam, litters were placed in a humid incubator kept at nest temperature $\left(34 \pm 1^{\circ} \mathrm{C}\right)$. Fifteen minutes before the test, pups were removed from the incubator, expressed of feces and urine, weighed as a litter, and then returned to the incubator until the test. In all cases, relative litter weight gains (RLWGs) are provided, i.e., litter weight gain in grams $/ 100 \mathrm{gm}$ of litter mass before testing.

Fos protocol. To evaluate Fos-immunoreactivity, we studied 40 lactating females ( $n=8$ per group). Each dam was separated from her litter beginning at 7:30 A.M.-12:30 P.M. on day 5 for $48 \mathrm{hr}$ before the test; we found previously that $c$-fos activation was unreliable after a $24 \mathrm{hr}$ separation, whereas display of maternal behavior within a $1 \mathrm{hr}$ test was unreliable after a $72 \mathrm{hr}$ separation. At the time of separation, each dam was rehoused individually in a clean, clear, pan cage with fresh bedding and placed in a room that contained no dams with litters. Two hours before the test, dams were moved in their cage to the observation room to allow for habituation. Litters to be used as stimuli were placed for 44 hr with a foster lactating dam, after which they were placed in the incubator until the test $4 \mathrm{hr}$ later. Fifteen minutes before the test, the mystacial pads of the pups were each injected subcutaneously with 0.025 $\mathrm{ml}$ of either isotonic saline (groups 1 and 3 ) or 2\% lidocaine (group 2). We verified that by $15 \mathrm{~min}$ after injection of lidocaine (Xylocaine, Astra Pharmaceutical Products, Westborough, MA), mystacial pads were anesthetized completely (lack of response to a reasonably strong pinch with forceps) and that pups so treated were incapable of attaching to a nipple for $\sim 75 \mathrm{~min}$ (Stern and Johnson, 1990). At the onset of the test on day 7 , eight pups were scattered opposite the nest site of the dam in groups 1 and 2; these pups were either capable of suckling (SK) or incapable of suckling (NSK), respectively. To establish that a possible elevation in Fos-immunoreactivity after physical interaction with pups is attributable to somatosensory input from the litter rather than to distal pup cues, nonspecific arousal, or general motoric activity, we presented additional groups of dams with eight pups in a box (P/B, group 3$)$ or an empty box (BOX, group 4). One of two double-ply wire-mesh boxes $(0.5 \times 0.5 \mathrm{~cm}$ mesh; $10 \times 10 \times 5 \mathrm{~cm}$ ) was placed in the front of the cage, each box dedicated to one of the conditions. Finally, group 5 dams received no stimulus in their cage (NO STIM), but their cage top was removed briefly and replaced at the beginning and end of the $60 \mathrm{~min}$ test period. After the 60 min observation, pups were immediately removed from the dam's cage and weighed; dams were killed $1 \mathrm{hr}$ later.

Lesion protocol. To evaluate the effects of cPAG lesions, we used 51 primiparous rats and their litters. In the first study (postpartum PAG-x), dams received bilateral sham $(n=10)$ or electrolytic $(n=13)$ lesions of the $\mathrm{cPAG}$ on day 7 postpartum. In the second study (prepartum PAG-x), subjects received bilateral sham $(n=11)$ or electrolytic $(n=17)$ lesions of the cPAG between days 15 and 17 of pregnancy. Between 8 and 9:30 A.M. beginning on day 1 (prepartum PAG-x) or day 5 (postpartum PAG-x), and continuing daily until the end of testing, each dam's rectal temperature was taken with a flexible rectal probe (Model 402) attached to a YSI telethermometer (Model 43TD; Yellowspring Instrument, Yellowspring, $\mathrm{OH}$ ). Dams and litters were then weighed, and litters were cross-fostered between lesioned subjects, sham-operated controls, and surrogate dams.

Mother-litter interactions were observed continuously after a $3 \mathrm{hr}$ dam-litter separation for 60 min on day 1-6 (prepartum PAG-x study) or for $45 \mathrm{~min}$ on day 6 (presurgically) and days 8-13 (postpartum PAG-x study). Maternal aggression was tested $\sim 1 \mathrm{hr}$ after the morning weighing by placing an unfamiliar male into the home cage opposite the nest. In the postpartum PAG-x study, the 10 min tests were carried out with the litter present on days 5 (presurgically), 8 , and 10 . Because attacks were frequent and pups were injured occasionally, in the prepartum PAG-x study the tests on days 2 and 6 occurred after removal of the litter and were reduced to $5 \mathrm{~min}$.

Behavioral observations. A computerized event recorder (S \& K Computer Products, Toronto, Ontario, Canada) was used for continuous observations, providing data on latency, frequency, and duration. Active behaviors directed toward pups included sniffing and licking, retrieval to the nest site, and mouthing (short-distance repositioning of the pups within the nest). Other active behaviors were self-grooming, exploration in or away from the nest (rearing, walking), digging/nesting (manipulation of bedding or paper), and eating or drinking.

Nursing behavior included hovering over the pups in the nest, while the dam was still motorically active, and motorically inactive kyphosis, with a low or high dorsal arch (Stern and Johnson, 1990). Additional nursing postures, pertinent to the lesion experiments, included lying prone over the pups (legs extended flat out, without support), lying supine (on side or back), and two partial kyphotic postures characterized by either hindlimb or forelimb support only. A stringent latency to quiescence was calculated as the time to a continuous period of $\geq 2 \min$ of quiescence, not interrupted by $>5 \mathrm{sec}$ of activity. Recorded pup behaviors included active rooting on the dam's ventrum by at least one pup and stretching of the litter in response to milk receipt (Drewett et al., 1974).

Aggressive behaviors of the dam (Stern and Kolunie, 1993) included sniffing the intruder, aggressive grooming (investigation of the male's snout and ears with the nose and mouth), kicking, and attacking (including lunging toward the intruder, tumbling, biting, and pinning). Dams' attack rate was determined by the number of attacks per minute after the first attack. In the prepartum PAG-x study, the upright defensive (boxing) and laterally orientated, offensive (sideways) postures were also quantified.

In the $c$-fos study, additional behaviors recorded for dams presented with the wire box, with or without pups inside, included sniffing, gnawing, or biting the box and standing on the box with at least two paws. NO STIM dams were observed briefly once every min for the first $10 \mathrm{~min}$ after cage top removal and then at 5 min intervals for the next $50 \mathrm{~min}$; therefore, only calculated estimations of general activity are reported. If a dam was seen to display a particular behavior, she was assigned that behavior for the duration of the 1 or 5 min time block until the beginning of the next spot check.

In the lesion studies, nest construction was evaluated by providing dams with two double-ply $16 \times 25 \mathrm{~cm}$ paper towels shredded and scattered in all quadrants of their home cage on the afternoons of days 5 and 9. Nests were rated early the next morning on a five-point scale (Numan and Callahan, 1980): 0 (no nest), 1 (poor, flat with not all material used), 2 (flat with all material used), 3 (good, with all material used to construct low walls), and 4 (excellent, with all material used to construct high walls).

Lesion surgery. Dams were anesthetized intraperitoneally with $70 \mathrm{mg} / \mathrm{kg}$ ketamine (Ketaset; Fort Dodge Laboratories, Fort Dodge, IA) and 5 $\mathrm{mg} / \mathrm{kg}$ xylazine (Rompun; Bayer, Shawnee Mission, KS) and then placed in a Kopf stereotaxic instrument. Dams received bilateral sham or electrolytic lesions of the cPAG using the following coordinates: anteroposterior $-7.4 \mathrm{~mm}$ from bregma, mediolateral $\pm 0.7 \mathrm{~mm}$, and dorsoventral $-6.4 \mathrm{~mm}$ (modified from Paxinos and Watson, 1986). After a $0.25-\mathrm{mm}-$ diameter monopolar electrode was lowered slowly, insulated except for $0.5 \mathrm{~mm}$ at the tip (Kopf, NE 300), $0.1 \mathrm{~mA}$ of direct current was passed for $45 \mathrm{sec}$ with a lesion-making device (UGO Basile, Model 3500) with a rectal probe as ground. After $2 \mathrm{~min}$, the electrode was removed and the contralateral side lesioned. Control subjects received similar treatment without the passage of current.

Preparation of brain sections. Dams were anesthetized deeply with 150 $\mathrm{mg} / \mathrm{kg}$ sodium pentobarbital (Nembutal; Abbott Laboratories, Chicago, IL). In the $c$-fos study, dams were then perfused through the heart with $200 \mathrm{ml}$ of PBS, followed by $200 \mathrm{ml}$ of $4 \%$ paraformaldehyde. Brains were 


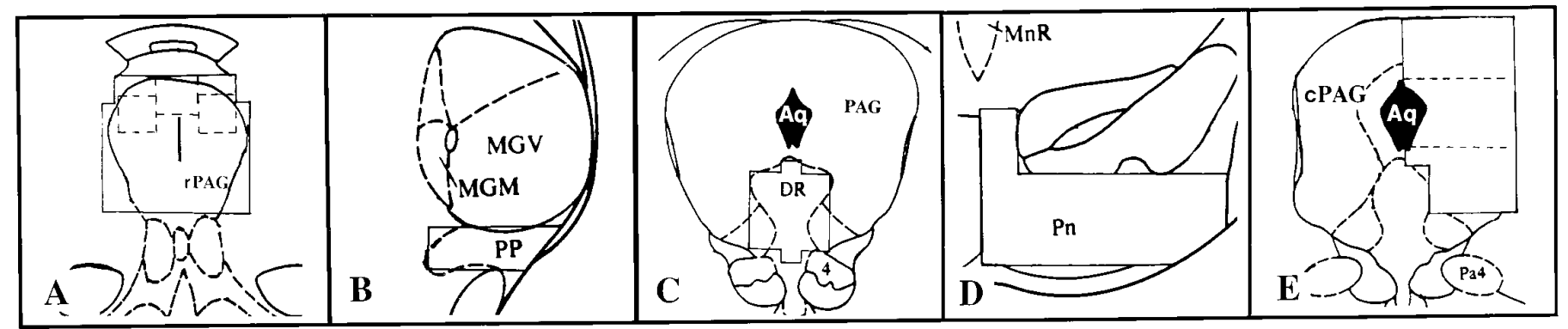

Figure 1. Diagrammatic representation (from Paxinos and Watson, 1986) of areas analyzed for Fos (arranged rostral to caudal). $A$, Rostral periaqueductal gray $(r P A G)$, with a single dorsomedial and bilateral dorsolateral subdivisions indicated by the dotted lines; $B$, peripeduncular nucleus $(P P)$; $C$, dorsal raphe nucleus $(D R) ; D$, pontine nucleus $(P n)$; and $E$, caudal periaqueductal gray $(c P A G)$, with dorsolateral, lateral, and ventrolateral subdivisions suggested by the dotted lines. $M G M$, Medial geniculate medial; $M G V$, medial geniculate ventral; 4, trochlear nucleus; $M n R$, median raphe; $A q$, aqueduct; $\mathrm{Pa}^{4}$, paratrochlear.

removed, post-fixed for $\sim 18 \mathrm{hr}$ and placed in $18 \%$ sucrose/paraformaldehyde solution with $0.001 \%$ thimerosal at $4^{\circ} \mathrm{C}$ until they were sectioned within $7 \mathrm{~d}$. Whole brains were cut into $50 \mu$ coronal sections on a freezing microtome, and the sections were stored at $4^{\circ} \mathrm{C}$ in PBS, pH 7.4, until they were processed within $48 \mathrm{hr}$.

In the lesion studies, anesthetized dams were perfused though the heart with $150 \mathrm{ml}$ of isotonic saline, followed by $150 \mathrm{ml}$ of $10 \%$ formalin Brains were removed and post-fixed for $24 \mathrm{hr}$, followed by submersion in $30 \%$ sucrose/formalin until they were sectioned. Brains were notched to maintain orientation, and the entire lesioned area was cut into $50 \mu$ sections on a freezing microtome, mounted onto gelatinized slides, and dehydrated. Sections were then stained with potassium ferrocyanide followed by counterstaining with Neutral Red, cleared in xylenes, and coverslipped. The extent of each lesion, including missing and coagulated tissue plus the surrounding halo of damaged cells, was reproduced on sequential atlas figures (Paxinos and Watson, 1986) using a Nikon Optiphot 2 microscope with a drawing tube attachment.

Immunocytochemistry was performed eight times; to reduce betweengroups variability in background staining, sections from one subject per group were processed simultaneously, every fifth section throughout the entire brain being processed for each subject. After three 5 min rinses in PBS, sections were washed in $0.1 \mathrm{~m}$ glycine for $30 \mathrm{~min}$, rinsed again three times, and washed in $0.5 \%$ hydrogen peroxide for $10 \mathrm{~min}$. After they were rinsed in PBS, sections were incubated for $72 \mathrm{hr}$ at $4^{\circ} \mathrm{C}$ with a rabbit affinity-purified polyclonal primary antibody (Oncogene Science, Manhassat, NY; lot 21930102; final dilution 1:750 in 0.3\% Triton X-100 solution) raised against the peptide corresponding to residues 4-17 of human Fos. This antiserum reacts with Fos protein, Fos-related antigens, and Fos-Jun heterodimers (Oncogene Science). Sections were rinsed three times in PBS and incubated for $1 \mathrm{hr}$ at room temperature $\left(\sim 22^{\circ} \mathrm{C}\right)$ with a biotin-SP-conjugated donkey anti-rabbit IgG secondary antibody (1:2500 in 3\% normal donkey serum; Jackson ImmunoResearch Laboratories, West Grove, PA). After sections were rinsed, they were processed further with avidin-biotin-horse radish peroxidase complex (Vector Labs, Burlingame, CA), and the peroxidase enzyme was visualized with a $3-3^{\prime}$ diaminobenzidine $(0.0125 \%)$ solution containing $0.06 \%$ hydrogen peroxide and $0.015 \% \mathrm{NiCl}$. As a control procedure, the primary Fos antiserum was omitted on certain sections, which abolished Fosimmunoreactivity staining. Sections were mounted on gelatin-coated slides, dehydrated, and coverslipped. Another series of alternate sections for each subject was stained with cresyl violet to facilitate accurate location of neuroanatomical regions.

Quantification of cells with Fos-immunoreactive (ir) nuclei. One section per subject for each site was used for analysis and was chosen primarily for its correspondence to the reference atlas plate and secondarily for histological quality. No attempt was made to choose sections with the most Fos-ir labeling. Subjects were randomized and coded for analysis. Areas of investigation were viewed with a Nikon Optiphot 2 light microscope at a magnification of $125 \times$ using methods similar to those of Heeb and Yahr (1996). A piece of graph paper $(24 \times 24 \mathrm{~mm}$ grid subdivided into $6 \times 6 \mathrm{~mm}$ squares) was viewed simultaneously with sections under analysis with the aid of a drawing tube. Areas of both the rostral PAG (rPAG) [atlas plate 38 (Paxinos and Watson, 1986), approximately -5.2 $\mathrm{mm}$ from bregma] and cPAG (plate $48,-7.6 \mathrm{~mm}$ ) were analyzed. Additionally, we quantified control nuclei, including the peripeduncular
(PP: plate 41, $-5.8 \mathrm{~mm}$ ), dorsal raphe (DR: plate $47,-7.3 \mathrm{~mm}$ ), and pontine (Pn: plate $47,-7.3 \mathrm{~mm}$ ), which is likely to be involved in all motor activity. Area of analysis consisted of a fixed number of adjacent grid squares that covered essentially the entire unilateral (cPAG, PP, Pn) or bilateral (rPAG, DR) extent of each structure (Fig. 1). Because the PAG consists of longitudinally oriented neuronal cell columns with different neuroanatomical connections and functions (Bandler et al., 1991), the rPAG was subdivided into dorsomedial, dorsolateral, and ventral regions, and the cPAG into dorsolateral, lateral, and ventrolateral regions for Fos-ir analysis.

All immunoreactive nuclei, regardless of intensity, lying fully within a particular square on the grid or overlapping its top or right edges (but not its bottom or left-hand borders), were directly quantified. This procedure eliminated the possibility of requantifying immunoreactive nuclei that lay on the shared border of two adjacent grid squares. All sites were analyzed by one observer (J.S.L.). The entire study (Lonstein et al., 1995) includes data on forebrain sites that will be reported elsewhere (J. S. Lonstein, D. A. Simmons, J. M. Swann, J. M. Stern, unpublished observations).

Data analyses. For the $c$-fos study, maternal and pup behaviors of the groups observed continuously were analyzed with the $t$-test or one-way ANOVA with Fisher's post hoc least squares difference (PLSD) test. Immunocytochemical results were analyzed with one-way ANOVAs and Fisher's PLSD tests. One subject in the BOX group was determined to be a statistical outlier in the number of Fos-ir cells analyzed (Dixon outlier test; $p<0.05$ ). Sections from a subject in the $\mathrm{P} / \mathrm{B}$ group were not analyzable because of inadequate perfusion and poor histology. These two subjects were replaced before completion of the study, and their brain sections were processed with those of five other subjects in the eighth immunocytochemical assay. For the lesion studies, behavioral data were analyzed with repeated measures ANOVA followed by Fisher's $t$ post hoc tests. Nest construction data were analyzed with Mann-Whitney $U$ tests. In the prepartum lesion experiment, one lesioned dam was an outlier with respect to the number of pups retrieved; these data were removed from the ANOVA.

\section{RESULTS}

\section{Effects of maternal and nonmaternal stimuli on behavior and activation of c-Fos in the brain}

\section{Behavioral differences between groups}

Dams separated from their litters were highly maternal when reunited with pups $48 \mathrm{hr}$ later, completing retrieval on average in $<50$ sec. Figure $2 A$ shows that dams in all four groups with a stimulus in their cage spent the majority of their time either interacting with the stimulus or engaging in other activity. Dams with a box, however, showed less time in physical contact with their stimulus item than did dams with accessible pups. The sum of all active behaviors reveals that NSK dams were significantly more active than SK dams, which became quiescent while nursing ( $\sim 34$ vs $\sim 23 \mathrm{~min}$ ), but less active than dams with a box, either with pups inside or empty $(\sim 42-44 \mathrm{~min})\left(F_{(3,28)}=7.23 ; p<\right.$ $0.001)$. In contrast, all NO STIM dams were active in the first 10 

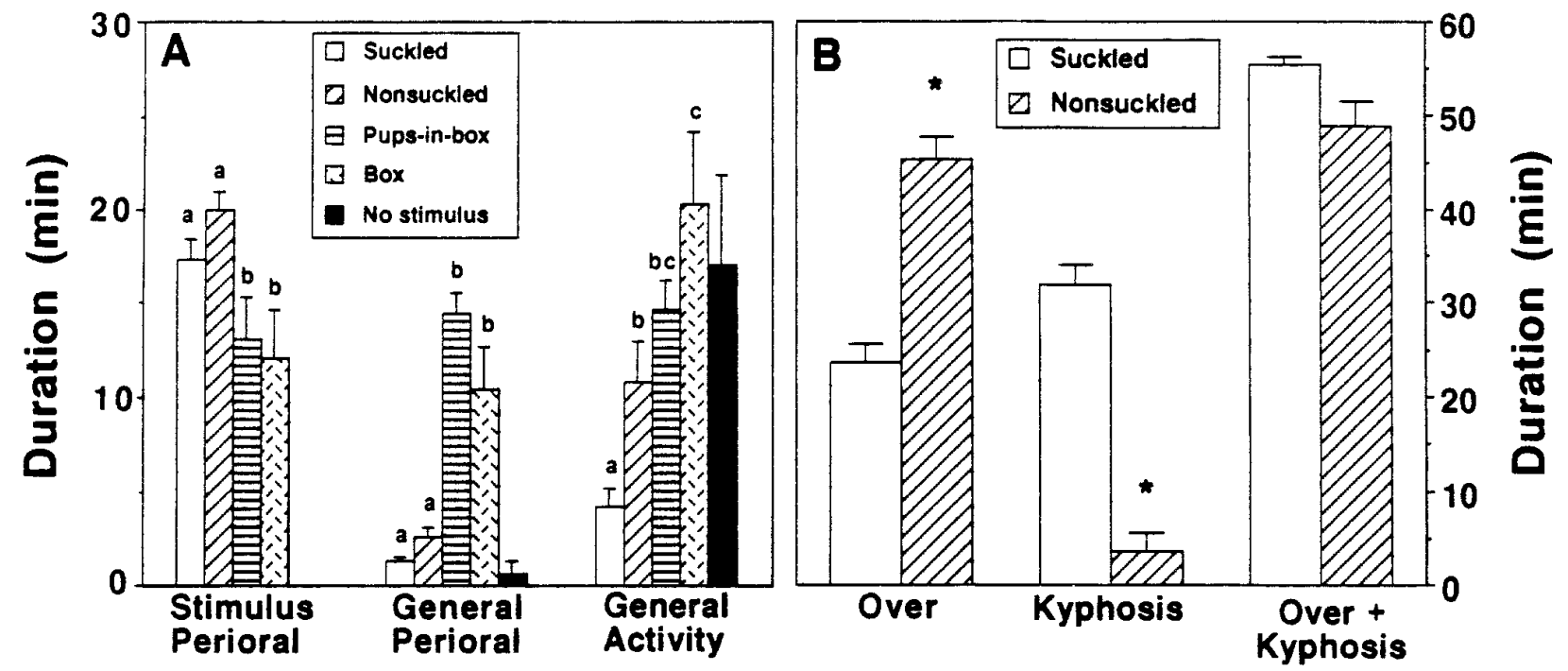

Figure 2. Effect of different stimulus conditions on the behavior (mean $\pm \mathrm{SEM}$ ) of lactating dams during a $1 \mathrm{hr}$ period. $A$, Stimulus-oriented perioral activity toward pups includes sniffing, licking, mouthing, and carrying of pups, and toward the box includes sniffing, gnawing, or biting the box; general perioral activity includes self-grooming, feeding, drinking, and tail retrieval; and general activity includes nest building, digging, and exploration (walking and rearing). The behavior of the No stimulus dams was estimated (see text). Statistically significant comparisons are indicated by different letters above the bars $(p \leq 0.05)$. B Hovering over (while active) and kyphotic crouching (while quiescent) by lactating dams physically interacting with SK or NSK pups. *, $p \leq 0.01$. Additional behavioral details will be reported by J. S. Lonstein, D. A. Simmons, J. M. Swann, J. M. Stern (unpublished observations).

min after brief removal of their cage tops, and then sporadically thereafter.

SK and NSK dams spent a comparable amount of time in the nest with their litter (Fig. 2B); however, NSK dams hovered over the litter while they were still active, including licking pups and self-grooming, twice as long as SK dams $(F=-6.91 ; p<0.0001)$, whereas SK dams spent ninefold more time than NSK dams actually nursing $(F=9.53 ; p<0.0001)$. This difference occurred despite comparable rooting time of pups $(\sim 13 \mathrm{~min})$, confirming the importance of SK stimulation for inducing kyphosis. All SK dams crouched after $\sim 10 \mathrm{~min}$, in both the high and low kyphotic postures, for $\sim 30 \mathrm{~min}$. In contrast, kyphosis occurred in only 3 of $8 \mathrm{NSK}$ dams, after a long latency $\left(\sim 29 \mathrm{~min} ; t_{(9)}=-5.70 ; p<\right.$ $0.0003)$, briefly $(<10 \mathrm{~min})$ and in only the low-arched posture. Individual bouts of kyphosis of $<2 \mathrm{~min}$, excluded in our previous analyses of nursing behavior (Stern and Johnson, 1990), constituted $38 \%$ of total crouching time for the three responding NSK dams, but only $5 \%$ of total crouching time for SK dams. Whereas SK litters displayed $5.4 \pm 0.8$ stretch responses and gained $2.6 \pm$ $0.6 \mathrm{gm}$, no NSK litter showed a stretch response and all lost weight $(-0.6 \pm 0.1 \mathrm{gm} ; t=5.18 ; p<0.0001)$. Visual inspection of the nipples of NSK dams after testing showed no evidence of suckling.

\section{Site differences in Fos-ir}

The only site at which SK dams had significantly more Fos-ir nuclei than NSK dams, which in turn had higher Fos-ir levels than the other groups, was the cPAG (Fig. 3). Labeling was found throughout the cPAG but tended to be denser in the lateral and ventrolateral regions (Fig. $4 A-C$ ). When subdivided into approximately equal thirds dorsoventrally (Table 1), similar group differences in Fos-ir labeling were found in the cPAG within the thirds ventrolateral and especially lateral to the cerebral aqueduct, whereas in the dorsolateral third, levels of Fos-ir were lower overall, and the pattern found in the other thirds was much less distinct. The three NSK dams showing short periods of kyphosis had levels of Fos-ir close to the mean of their group.

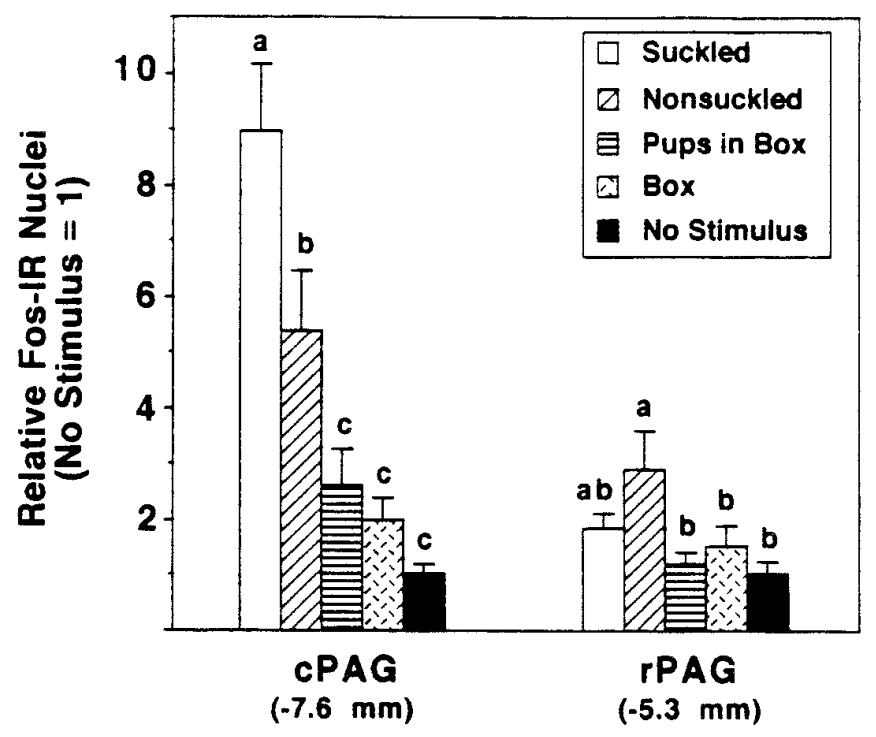

Figure 3. Number (mean \pm SE) of Fos-ir nuclei in the rostral and cPAG expressed relative to the mean of the No Stimulus control group; statistically significant comparisons are indicated by different letters above the bars $(p \leq 0.05)$.

In the rPAG, NSK dams had the highest levels of Fos-ir, significantly greater than the similarly low levels in $\mathrm{P} / \mathrm{B}, \mathrm{BOX}$, and NO STIM dams, with intermediate levels seen in SK dams (Fig. 3 ). Labeling was confined primarily to the dorsomedial and dorsolateral aspects (Fig. 4D; Table 1). In fact, $46 \%$ of the total Fos-ir was found in the delineated dorsomedial and dorsolateral sections, which together represent only $\sim 20 \%$ of the total area analyzed for the rPAG. No group differences in Fos-ir were found in the dorsomedial portion, but group differences similar to those observed for the entire rPAG were found in the dorsolateral 

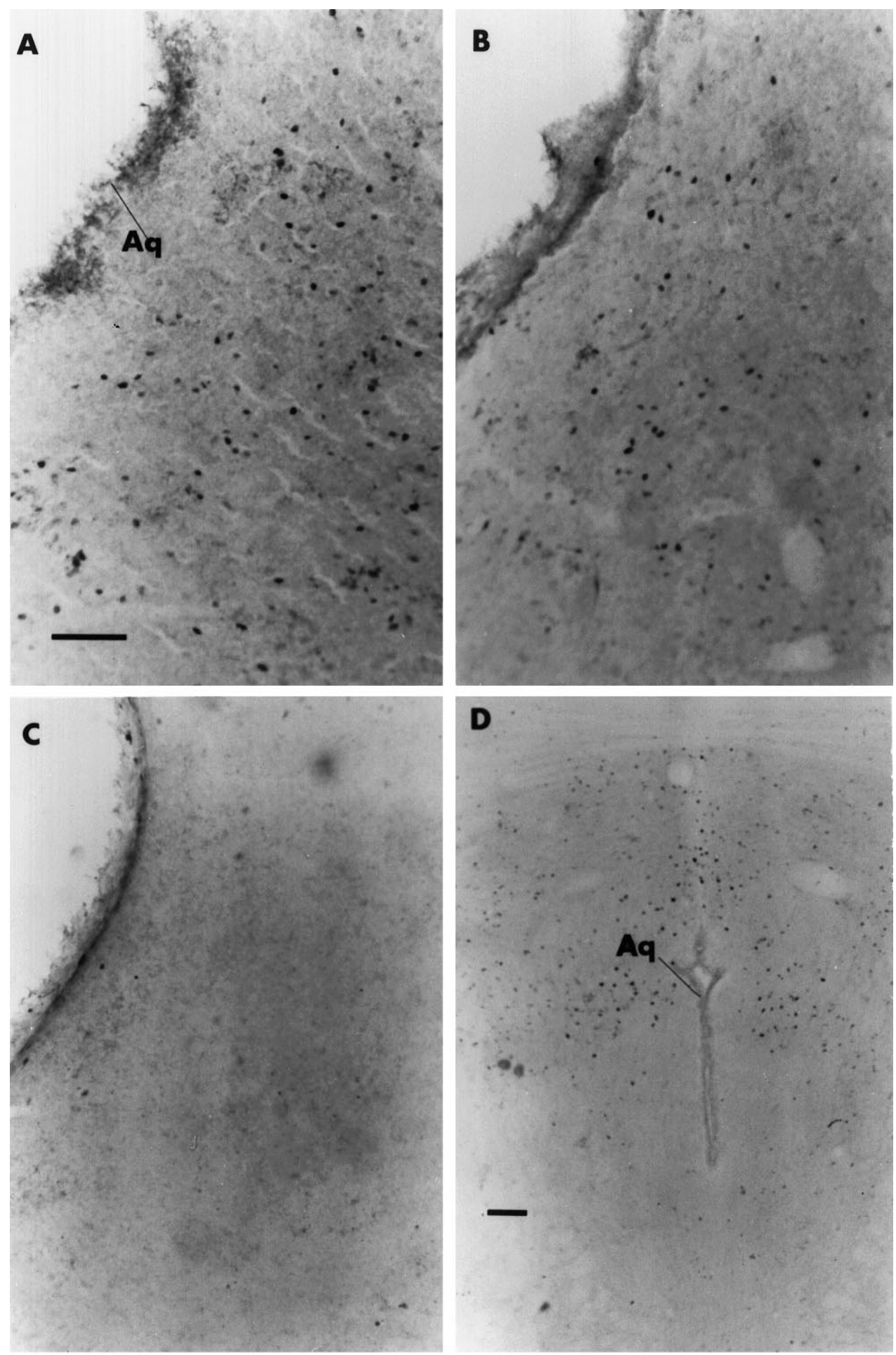

Figure 4. Photomicrographs of cPAG in a representative dam in each of three groups: $A$, SK; $B$, NSK; $C$, no stimulus. $D$, Photomicrograph of rPAG in a representative NSK dam, where Fos is concentrated in the dorsal and dorsolateral regions. Scale bar, $100 \mu \mathrm{m}$.

portion and in the balance of rPAG. There were no significant group differences in Fos-ir labeling in the PP, DR, or Pn nuclei (Table 1). In addition, the ventral tegmental area and the spinal trigeminal nuclei (caudalis, interpolaris, oralis, principle) were found by inspection to have little or no Fos in any subject and therefore were not quantified.

\section{Effects of lesions on the cPAG}

\section{Histological analysis of prepartum PAG lesions}

Seven subjects with misplaced lesions were excluded from statistical analyses, four with only a unilateral lesion of the $\mathrm{CPAG}_{1, \mathrm{vl}}$, one with a unilateral $\mathrm{CPAG}_{1, \mathrm{vl}}$ lesion and a contralateral superior 


\begin{tabular}{|c|c|c|c|c|c|c|c|}
\hline Site & SK & NSK & $\mathrm{P} / \mathrm{B}$ & BOX & $\begin{array}{l}\text { NO } \\
\text { STIM }\end{array}$ & $F_{(4,35)}$ & $p$ \\
\hline cPAG & $199 \pm 27^{a}$ & $128 \pm 25^{b}$ & $60 \pm 15^{c}$ & $49 \pm 9^{c}$ & $22 \pm 5^{c}$ & 15.80 & 0.0001 \\
\hline $\mathrm{cPAG}_{1}$ & $71 \pm 7^{a}$ & $39 \pm 11^{b^{*}}$ & $15 \pm 4^{c}$ & $12 \pm 3^{c}$ & $4 \pm 1^{c}$ & 18.76 & 0.0001 \\
\hline $\mathrm{cPAG}_{\mathrm{v} 1}$ & $91 \pm 13^{a}$ & $59 \pm 11^{b+}$ & $28 \pm 10^{c}$ & $17 \pm 4^{c}$ & $11 \pm 3^{c}$ & 14.01 & 0.0001 \\
\hline $\mathrm{cPAG}_{\mathrm{dl}}$ & $37 \pm 8^{a}$ & $30 \pm 5^{a b}$ & $17 \pm 5^{b c}$ & $20 \pm 3^{b c}$ & $7 \pm 2^{c}$ & 5.20 & 0.0021 \\
\hline rPAG & $149 \pm 22^{a b}$ & $236 \pm 54^{a}$ & $97 \pm 19^{b}$ & $124 \pm 29^{b}$ & $81 \pm 29^{b}$ & 3.71 & 0.0127 \\
\hline $\mathrm{rPAG}_{\mathrm{dl}}$ & $50 \pm 6^{a b}$ & $72 \pm 15^{a}$ & $29 \pm 6^{b}$ & $37 \pm 8^{b}$ & $28 \pm 6^{b}$ & 4.22 & 0.0068 \\
\hline $\mathrm{rPAG}_{\mathrm{dm}}$ & $20 \pm 5$ & $18 \pm 6$ & $19 \pm 5$ & $22 \pm 6$ & $23 \pm 6$ & 0.12 & 0.9729 \\
\hline $\mathrm{rPAG}_{\mathrm{bal}}$ & $79 \pm 17^{a b}$ & $146 \pm 43^{a}$ & $49 \pm 13^{b}$ & $65 \pm 18^{b}$ & $30 \pm 11^{b}$ & 3.52 & 0.0161 \\
\hline $\mathrm{PP}$ & $29 \pm 4$ & $26 \pm 7$ & $25 \pm 6$ & $33 \pm 5$ & $22 \pm 7$ & 0.42 & 0.7946 \\
\hline DR & $39 \pm 9$ & $36 \pm 10$ & $17 \pm 4$ & $26 \pm 5$ & $16 \pm 6$ & 2.19 & 0.0910 \\
\hline $\mathrm{Pn}$ & $314 \pm 36$ & $255 \pm 52$ & $272 \pm 58$ & $331 \pm 31$ & $178 \pm 49$ & 1.66 & 0.1810 \\
\hline
\end{tabular}

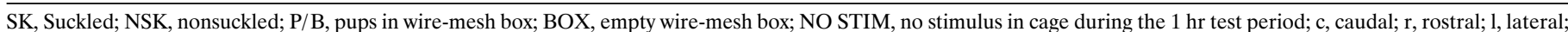

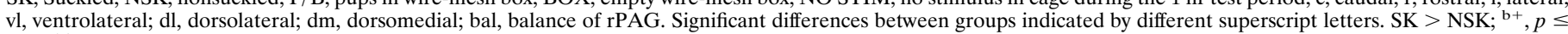
$0.02,{ }^{b^{*}} p \leq 0.001$.

colliculus lesion, one with a bilateral lesion of the dorsal cPAG and deep layers of the superior colliculus, and one with a bilateral lesion of the cPAG caudal to the intended site, which extended into the dorsal medulla and cerebellum. The remaining subjects $(n=10)$ all received bilateral damage to the $\mathrm{CPAG}_{1, \mathrm{vl}}$, primarily at intercollicular levels, all lesions encompassing at least a $1.5 \mathrm{~mm}$ area from -6.7 to $-8.2 \mathrm{~mm}$ from bregma (Fig. 5). Individual lesions typically extended $\sim 1.9 \mathrm{~mm}$ rostrocaudally, with none extending rostrally beyond $-5.8 \mathrm{~mm}$ or caudally beyond $-8.8 \mathrm{~mm}$. In 3 of 10 cases, damage extended into the dorsal half of the PAG. In two cases damage extended unilaterally into the tegmentum surrounding the PAG. Rostrally, four lesions involved damage at least unilaterally to the supraoculomotor central gray and parvocellular oculomotor nucleus, but none to the oculomotor nucleus itself. Caudally, four lesions involved slight damage, and two involved larger damage, to DR.

\section{Histological analysis of postpartum PAG lesions}

One dam with no discernible lesion and another with a misplaced lesion-more caudally in the ventrolateral PAG, bilaterally, with extension into the cerebellum and dorsomedial medulla-were not included in statistical analyses. The remaining lesioned subjects $(n=11)$ all sustained restricted bilateral damage to the region of the $\mathrm{cPAG}$ immediately lateral to the cerebral aqueduct, primarily at intercollicular levels, all lesions encompassing at least a $1.2 \mathrm{~mm}$ area from -6.7 to $-7.9 \mathrm{~mm}$ from bregma (Fig. 5). Individual lesions were generally smaller than those of prepartum lesioned subjects, typically extending $\sim 1.4 \mathrm{~mm}$ rostrocaudally, with none extending beyond $-6.2 \mathrm{~mm}$ rostrally or $-8.3 \mathrm{~mm}$ caudally from bregma. In no cases did primary damage extend laterally into the surrounding tegmentum. In 10 of 11 cases, there was substantial damage to the $\mathrm{cPAG}_{1, \mathrm{vl}}$, and in one case equal damage to the dorsolateral and ventrolateral $\mathrm{cPAG}$, the damage to the latter being less than that of the other subjects. Rostrally, 5 of 11 lesions involved minor damage at least unilaterally to the supraoculomotor central gray and parvocellular oculomotor nucleus, but in no case to the oculomotor nucleus itself. Caudally, 6 of 11 lesions involved very minor damage at least unilaterally to dorsolateral areas of the DR nucleus. Little or no tissue damage was evident in sham-lesioned dams in either study.

\section{General condition}

All subjects recovered successfully from surgery and were in excellent condition postsurgically, with none showing profound aphagia or adipsia associated with large PAG lesions (Van Erp et al., 1993). Indeed, both lesioned and control dams from both experiments gained similar amounts of weight over the duration of the experiment, and no group differences were found in dam core temperature (Table 2). Spontaneous and repetitive "galloping" or jumping behavior, which we saw in preliminary work after larger lesions of the PAG (cf. Hennessey et al., 1990), were not seen in any case included in the present report. The excluded subject in the postpartum lesion experiment with a cPAG lesion that extended caudally into both the cerebellum and medulla showed severe retrieval deficits and very low kyphosis durations during all postsurgical tests.

\section{Motorically active behaviors}

PAG-x and control dams were remarkably similar in their display of active behaviors, whether the surgery was carried out pre- or postpartum (Table 2). Retrieval behavior was essentially normal after the $\mathrm{cPAG}_{1, \mathrm{vl}}$ was lesioned. Lesioned and sham groups were similar in the number of pups retrieved (Fig. 6A,B) and latency to retrieve the first pup (Fig. $6 C, D$ ). In the postpartum PAG-x study, both groups of dams retrieved fewer pups as the pups became older and more mobile (day $F_{(1,6)}=10.4 ; p<0.0001$ ). Both pre- and postpartum PAG-x dams, however, tended to be slower to complete retrieval of each pup (Fig. $6 E, F$ ), mostly because of a delay of a few seconds between bringing the pup to the nest and actually depositing it there. Duration of licking (Fig. 6G,H), sniffing, and mouthing the pups did not differ between groups in either experiment. Time spent manipulating nest material and wood shavings was similar for both groups in the prepartum lesion experiment, but lower in postpartum PAG-X dams; however, ratings of nest construction of the postpartum dams on days 5 and 9 did not differ between groups $(p>0.05)$. Durations of other active behaviors, including self-grooming and cage exploration, were also not affected by $\mathrm{cPAG}_{1, \mathrm{vl}}$ lesions performed either preor postpartum (Table 2).

\section{Nursing behavior}

Total time in physical contact with the pups during the daily observations did not differ between lesioned and sham groups operated on either pre- or postpartum (Table 2). Prepartum PAG-x dams spent $\sim 15 \%$ more time actively hovering over their pups in the nest $\left(F_{(1,19)}\right.$ $=4.2 ; p<0.06)$, but postpartum PAG-x dams were similar to their controls $\left(F_{(1,19)}=0.05 ; p>0.8\right)$. Although the latency to begin quiescently nursing the pups from the beginning of the test was 


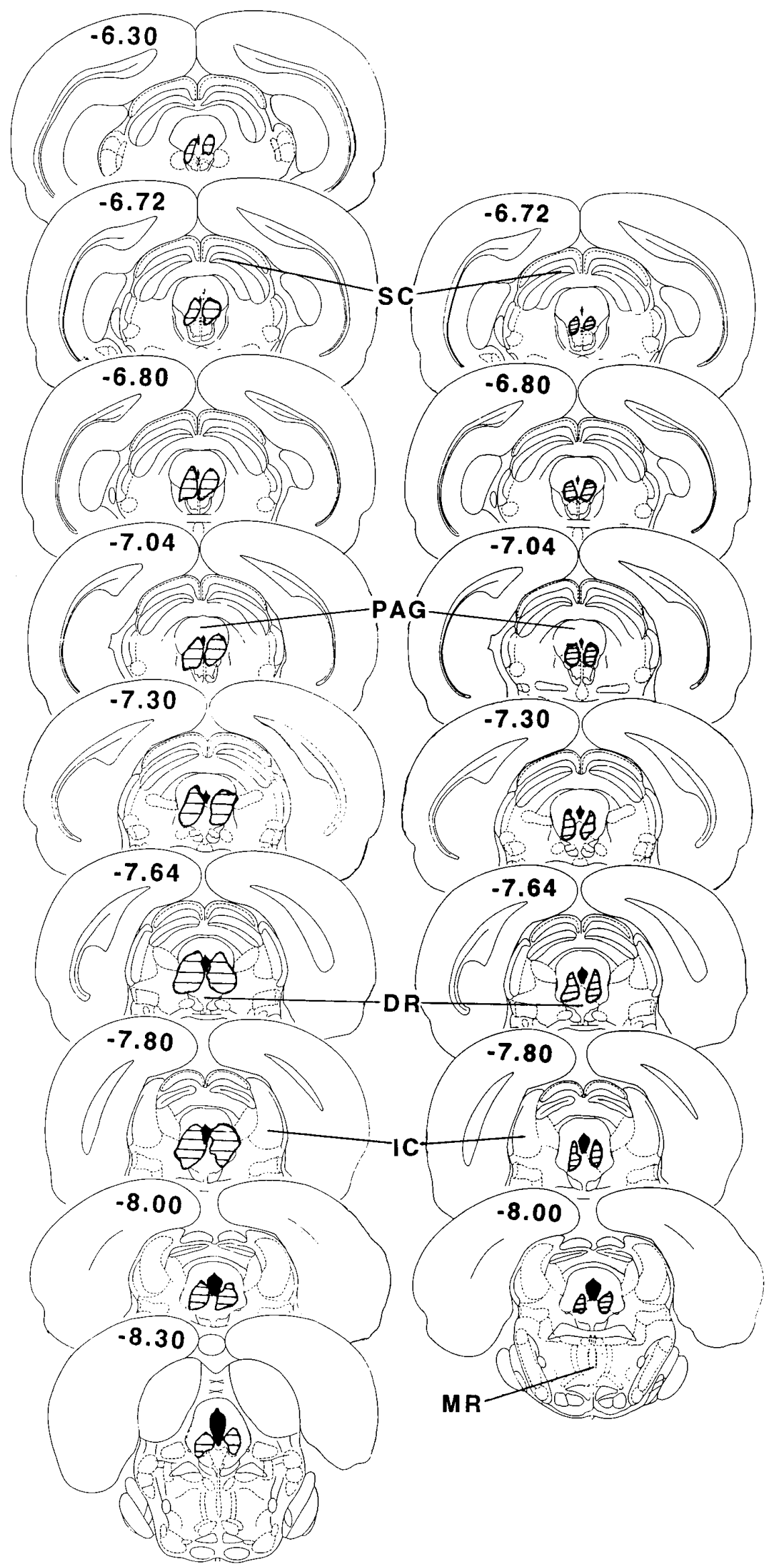

Figure 5. Reconstruction of representative prepartum (left) and postpartum (right) electrolytic lesions of the $\mathrm{CPAG}_{1, \mathrm{vl}}$ (modified from Paxinos and Watson, 1986). SC, Superior colliculus; $P A G$, periaqueductal gray; $D R$, dorsal raphe; $I C$, inferior colliculus; $M R$, median raphe. 
Table 2. Effects of lesions to the cPAG $_{1, v l}$ (PAG-x) carried out prepartum (gestation day 15-17) or postpartum (day 7) on rat dams' weight, body temperature, and behavior (means \pm SEM) during a 60 or 45 min (respectively) interaction with pups

\begin{tabular}{|c|c|c|c|c|c|c|}
\hline \multirow[b]{2}{*}{ Measure } & \multicolumn{3}{|c|}{ Prepartum experiment: mean of days $1-6$} & \multicolumn{3}{|c|}{ Postpartum experiment: mean of days $8-13$} \\
\hline & Sham & PAG-x & $F_{(1,19)}$ & Sham & PAG-x & $F_{(1,19)}$ \\
\hline Body weight (gm) & $341 \pm 8$ & $350 \pm 8$ & 0.59 & $337 \pm 6$ & $334 \pm 5$ & 0.13 \\
\hline Body temperature $\left({ }^{\circ} \mathrm{C}\right)$ & $38.5 \pm 0.1$ & $38.6 \pm 0.8$ & 0.14 & $38.6 \pm 0.1$ & $38.6 \pm 0.1$ & 0.001 \\
\hline \multicolumn{7}{|l|}{ Latency $(\mathrm{sec})$} \\
\hline Hover over & $87 \pm 3$ & $149 \pm 42$ & 2.48 & $79 \pm 8$ & $107 \pm 6$ & $8.9^{*}$ \\
\hline Quiescence & $682 \pm 72$ & $1416 \pm 84$ & $44.1^{* *}$ & $461 \pm 44$ & $1013 \pm 61$ & $50.6^{* *}$ \\
\hline \multicolumn{7}{|l|}{ Behavior duration $(\mathrm{sec})$} \\
\hline Mouth pups & $6.0 \pm 1.0$ & $5.8 \pm 1.0$ & 0.02 & $5.3 \pm 1.1$ & $9.9 \pm 1.8$ & $5.72 *$ \\
\hline Nest, burrow & $108 \pm 22$ & $67 \pm 10$ & 2.67 & $111 \pm 28$ & $41 \pm 11$ & $5.53^{*}$ \\
\hline Self-groom & $182 \pm 18$ & $181 \pm 20$ & 0.04 & $95 \pm 27$ & $93 \pm 11$ & 0.01 \\
\hline Walk, rear & $160 \pm 17$ & $184 \pm 37$ & 0.38 & $108 \pm 22$ & $66 \pm 12$ & 2.22 \\
\hline Hover over & $1283 \pm 75$ & $1536 \pm 101$ & $4.15^{\dagger}$ & $908 \pm 79$ & $934 \pm 64$ & 0.05 \\
\hline All nursing & $1868 \pm 102$ & $1588 \pm 107$ & $3.58^{\dagger}$ & $1409 \pm 129$ & $1461 \pm 85$ & 0.08 \\
\hline Over + nursing & $3151 \pm 70$ & $3124 \pm 67$ & 0.07 & $2317 \pm 79$ & $2396 \pm 39$ & 0.64 \\
\hline Partial kyphosis & $96 \pm 31$ & $265 \pm 76$ & $4.61^{*}$ & $3.8 \pm 2.9$ & $11.6 \pm 5.5$ & 1.34 \\
\hline
\end{tabular}

ANOVA values of data from postpartum experiment include the presurgery baseline data (day 6 ). ${ }^{\dagger} p<0.10 ;{ }^{*} p \leq 0.05 ; * * p \leq 0.001$.

approximately twice as long for PAG-x dams compared with controls in both experiments, the total duration of quiescent nursing in all postures, $\sim 50 \%$ of the observation time, did not differ significantly between groups on any day.

Once quiescent, however, PAG-x dams did not show normal nursing behavior. In prepartum PAG-x dams, kyphosis was reduced $85 \%$, the full effect being present on the first test day, 7-9 d postsurgery (Fig. $7 A$ ). In postpartum PAG-x dams, kyphosis was similar in duration between groups presurgically on day 6 and was nearly eliminated after lesioning but not sham surgery, with no evidence of recovery; however, it took until $2 \mathrm{~d}$ after surgery (day 9) for the full effects of the lesion to be evident (Fig. 7B). For both experiments, the maximum sustained duration of kyphosis within a nursing bout was only 1-2 min in PAG-x dams versus $10-15 \mathrm{~min}$ in controls (Fig. 7C,D). In compensation for the near-absence of kyphosis, PAG-x dams nursed their litters primarily in the prone (Fig. $7 E, F$ ) and supine (Fig. $7 G, H$ ) positions during the entire postlesion period, uncharacteristic of controls in this testing situation. As a group, the seven prepartum lesioned dams with unilateral cPAG or misplaced lesions, or both, showed $\sim 15$ min of kyphosis each day of testing, which was $40 \%$ less than that displayed by sham controls but almost four times more than that shown by bilaterally $\mathrm{cPAG}_{1, \mathrm{vl}}$-lesioned dams.

\section{Litter weight gains}

All dams lactated postsurgery, $24 \mathrm{hr}$ RLWGs being $~ 26 \%$ and $\sim 15 \%$ less for litters interacting with prepartum and postpartum lesioned dams, respectively, compared with controls $\left(F_{(1,19)}=\right.$ 18.2, $\left.p<0.0004 ; F_{(1,19)}=7.1, p<0.0155\right)$ (Fig. 8A,B). Litters of both lesioned and sham-lesioned dams gained weight during the daily 60 or 45 min dam-litter interactions, increasingly over time postpartum ( $p<0.0001$ ) (Fig. 8C,D); these gains were 16 and $20 \%$ less overall in litters suckling prepartum lesioned $\left(F_{(1,19)}=\right.$ $1.26 ; p<0.2755)$ and postpartum lesioned $\left(F_{(1,19)}=6.49 ; p<\right.$ $0.0197)$ dams. Although large lesions of serotonergic perikarya in DR reduce hypothalamic serotonin necessary for sucklinginduced prolactin release (Borofsky et al., 1983), daily RLWGs did not differ between prepartum or postpartum PAG-x dams, with some $(n=6,6)$ or no $(n=4,5)$ DR damage $(p>0.9,0.3)$.
Pup stretch responses (PSRs), indicative of milk letdown, were reliably detectable from day 5 on; the number of PSRs did not differ between groups in either experiment. In the postpartum PAG-x study, PSRs during the daily mother-litter observation increased in frequency, from 4.3 to 7.1 , day 6 to $13(p<0.0001)$, similarly for both groups. The latency to the first PSR from the beginning of the test was $38 \%$ longer on days 5 and 6 for prepartum PAG-x dams than sham controls $(1599 \pm 138$ vs $997 \pm 69 \mathrm{sec}$; $\left.F_{(1,19)}=16.2 ; p<0.0007\right)$ and $26 \%$ longer across all postsurgical days in the postpartum experiment $\left(F_{(1,19)}=10.59 ; p<0.0042\right)$ (Fig. $8 E$ ). Latency of the last PSR did not differ between groups of postpartum lesioned dams, indicating more rapid milk letdowns in PAG-x dams after their late onset.

\section{Maternal aggression}

On each test, all dams attacked the male at least once, but PAG-x dams were substantially more aggressive than controls (Table 3). Latency to attack from the beginning of the test was somewhat shorter in prepartum PAG-x rats $\left(F_{(1,19)}=3.02 ; p<0.10\right)$, especially on day 2 , and in postpartum PAG-x rats only on day 10 $\left(t_{(19)}=1.99 ; p=0.06\right.$ ) (Fig. 9A,B). In the prepartum study, PAG-x dams displayed a significant increase in attack frequency compared with controls on both test days (1.7-fold in $5 \mathrm{~min}$ ), whereas in the postpartum study, a significant postsurgical increase was evident on day 10 (2.4-fold in $10 \mathrm{~min}$; Table 3). Similar differences were found in attack rate per minute calculated from the onset of attacking (prepartum: $F_{(1,19)}=20.51, p<0.001$; postpartum: group $\times$ day, $\left.F_{(1,2)}=8.90, p<0.001\right)$ (Fig. 9C,D). The mean attack duration per bout was $40 \%$ longer in prepartum PAG-x dams, but it did not differ between postpartum PAG-x and control dams (Table 3 ). In both pre- and postpartum experiments, the duration of aggressive grooming was significantly shorter after PAG-x (Table 3) and correlated significantly on the last test day with attack latency $(r=0.463$ and $0.582, p<0.04$ and 0.01 , respectively). Prepartum PAG-x dams displayed the sideways posture for half as long and boxing for more than twice as long as controls (Table 3 ). In both experiments, duration of sniffing did not differ between groups (Table 3), and there was little or no kicking. The seven prepartum PAG-x dams with unilateral cPAG 


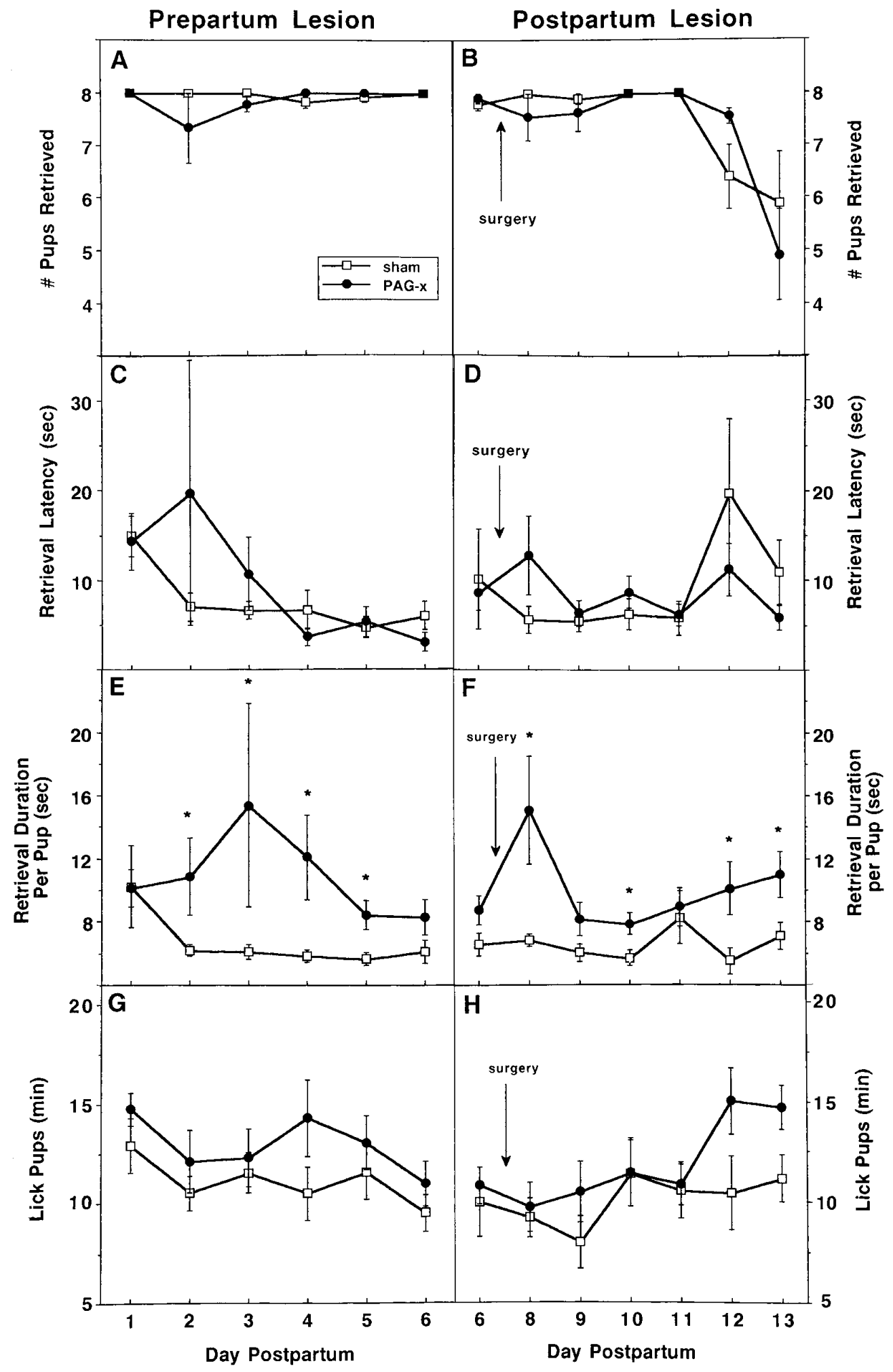

Figure 6. Effects of prepartum (left) or postpartum (right) sham (unfilled squares) or cPAG ( filled circles) lesions on active maternal behavior (mean \pm SEM) in daily $60 \mathrm{~min}($ left) or $45 \mathrm{~min}$ (right) interactions with the litter, after a $3 \mathrm{hr}$ dam-litter separation during the first (left) or second (right) week postpartum. $A, B$, Number of pups retrieved; $C, D$, latency (sec) to retrieve the first pup; $E, F$, (latency to retrieve the last pup) - (latency to retrieve the first pup)/number of pups retrieved (sec); and $G, H$, duration of licking pups (min). 


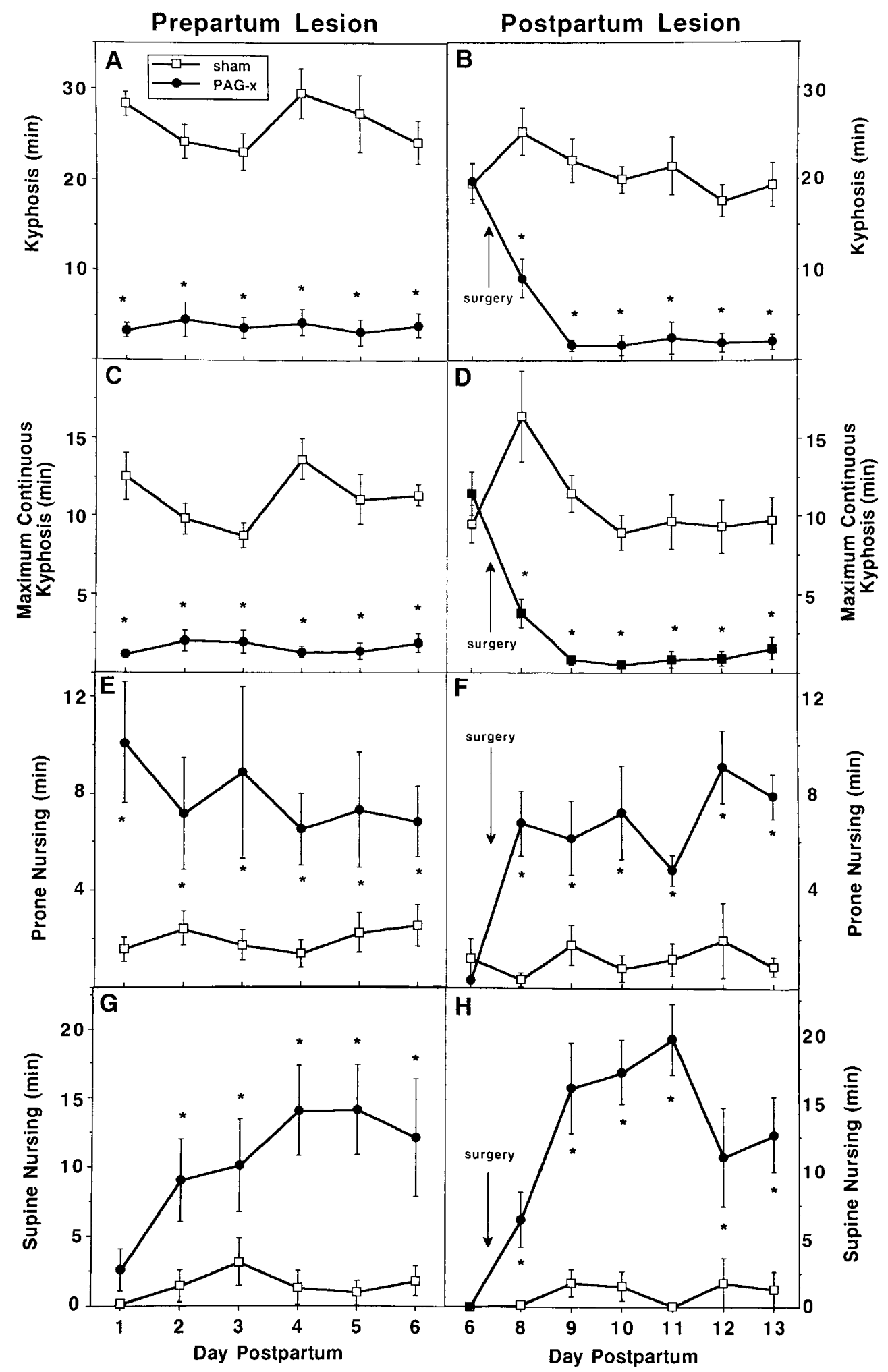

Figure 7. Effects of prepartum (left) or postpartum (right) sham (unfilled squares) or cPAG lesions on duration of nursing postures (mean min \pm SEM) in daily $60 \mathrm{~min}$ (left) or $45 \mathrm{~min}$ (right) interactions with the litter, after a $3 \mathrm{hr}$ dam-litter separation during the first (left) or second (right) week postpartum. $A, B$, Kyphosis; $C$, $D$, maximum sustained kyphosis within a nursing bout; $E, F$, nursing while lying prone over the litter; and $G$, $H$, nursing while supine on back or side. ${ }^{*} p \leq 0.05$. 

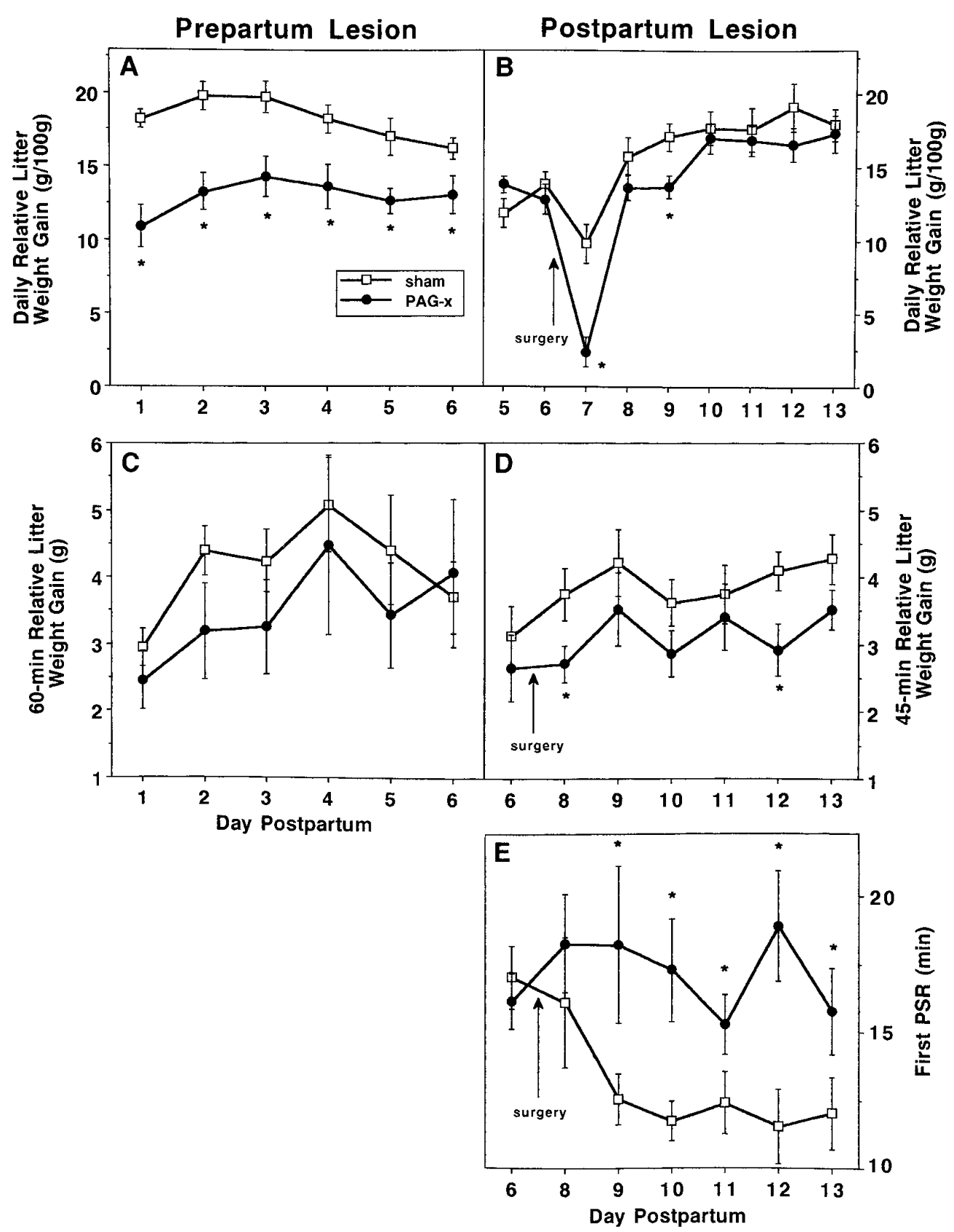

Figure 8. Effects of prepartum (left) or postpartum (right) sham (unfilled squares) or cPAG ( filled circles) lesions on indices of lactation (mean \pm SEM) during the first (left) or second (right) week of lactation. $A, B$, Daily relative litter weight gains $(\mathrm{gm})$; $C, D$, relative litter weight gains during daily 60 min (left) or 45 min (right) behavioral observations; and $E$, latency to first PSR, indicative of the dam's milk ejection. * $p \leq 0.05$.

or misplaced lesions, or both, showed aggressive behavior similar to that of sham controls (e.g., attack frequency means: 6 vs 7, day 2 ; 10 vs 8 , day 6$)$.

\section{DISCUSSION}

Using visualization of Fos-ir, we identified a midbrain site, the lateral and ventrolateral regions of the PAG at intercollicular levels, that responds maximally to suckling stimulation, a pattern not found in six other brainstem structures, including the PAG rostral or caudal to this area (this report; Stern et al., 1997) or in 20 forebrain sites (Lonstein et al., 1995; J. S. Lonstein, D. A. Simmons, J. M. Swann, J. M. Stern, unpublished observations). Electrolytic lesions of the $\mathrm{CPAG}_{1, \mathrm{vl}}$, performed either prepartum or postpartum, demonstrated specific roles for this region in mediating the kyphotic nursing posture and in modulating maternal aggression toward an intruder, with no recovery up to 2 weeks postlesioning. These behavioral effects of $\mathrm{cPAG}_{1, \mathrm{vl}}$ lesions are not attributable to gross alterations in somatosensory perception, because lesioned dams showed essentially normal retrieval and licking of pups and quiescent nursing in all postures combined of similar duration to that of controls, and they had milk letdowns, functions disrupted by perioral or ventral desensitizations (Stern, 1996a). Furthermore, $\mathrm{CPAG}_{1, \mathrm{vl}}$-lesioned dams showed normal recuperative behavior to noxious somatosensory stimulation (Lonstein et al., 1997). The uniqueness of the small $\mathrm{CPAG}_{1, \mathrm{vl}}$ region 
Table 3. Effects of lesions to the $\mathrm{cPAG}_{\mathrm{l}, \mathrm{vl}}$ (PAG-x) carried out prepartum (gestation day 15-17) or postpartum (day 7) on lactating rat dams' behavior (means \pm SEM) toward a strange male intruder (maternal aggression) in 5 or 10 min tests, respectively

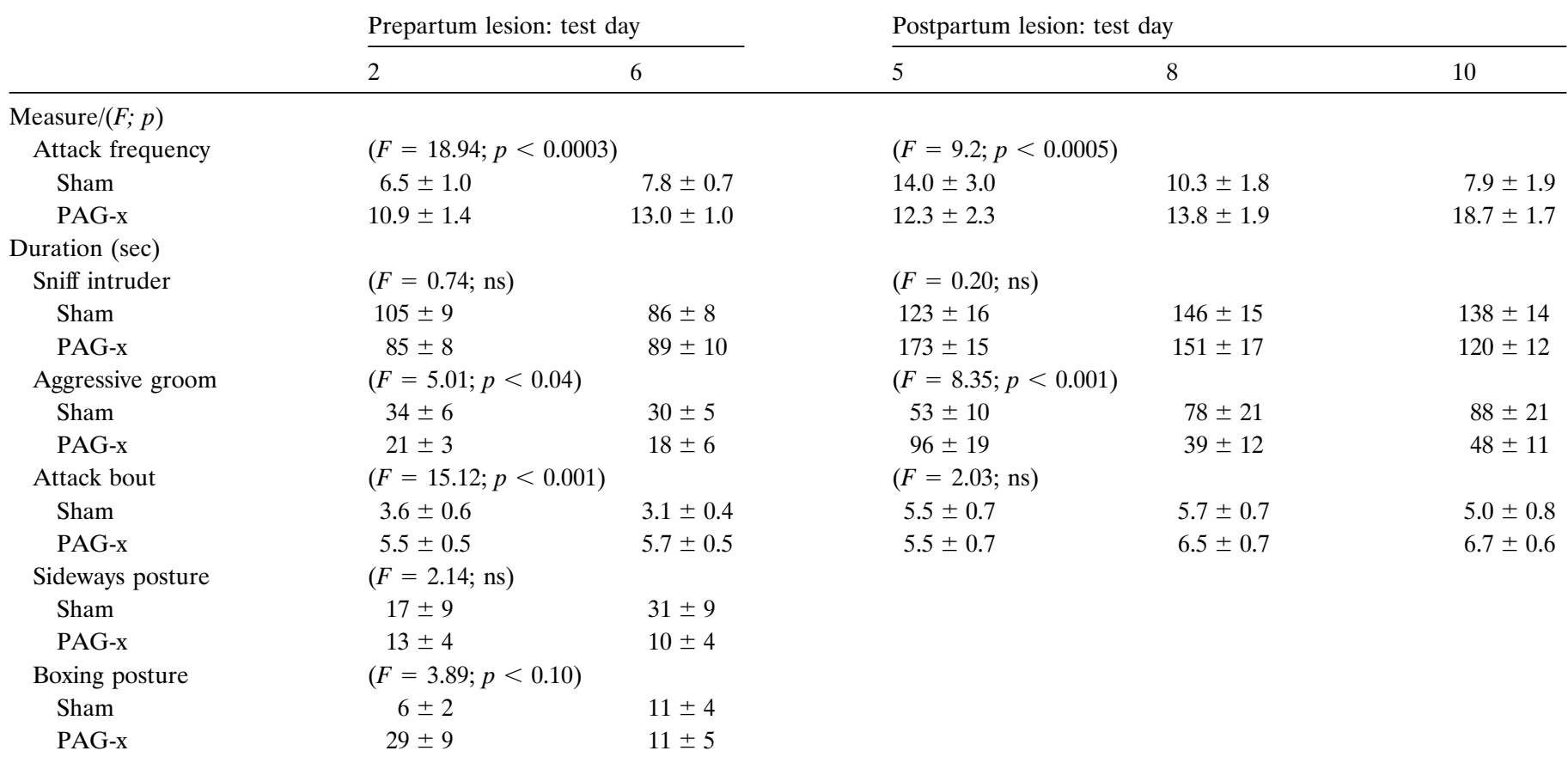

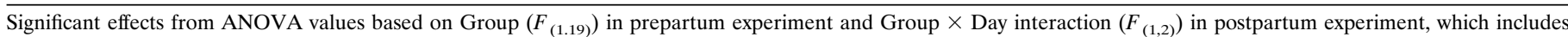
presurgery baseline (day 5); $n s$, no statistically significant effects.

lesioned herein is evident because no other brain lesion is known to either specifically impair the kyphotic nursing posture (Stern, 1989; Numan, 1994) or heighten maternal aggression.

\section{Effects of SK or NSK contact on Fos-ir expression in the PAG}

SK stimulation specifically elevates $c$-fos compared with NSK stimulation in the cPAG, but not in $>27$ other brain sites, including the paraventricular and supraoptic nuclei (this report; Lonstein et al., 1995; J. S. Lonstein, D. A. Simmons, J. M. Swann, J. M. Stern, unpublished observations). The absence of Fos-ir in these oxytocin-synthesizing structures in response to SK is attributed to a hypothalamic gating mechanism that results in brief bursts of discharges before oxytocin release but an overall lower rate of action potentials than that resulting from conditions such as parturition that do activate Fos-ir in these sites (Fénelon et al., 1993). In contrast, the robust activation of Fos-ir in the cPAG after SK may reflect ungated input comparable to that found in the dorsal horn of SK rats (Fénelon and Poulain, 1992) or proprioceptive feedback from the sustained kyphotic nursing posture (cf. Yezierski and Schwartz, 1986), or both.

NSK contact with pups resulted in significantly more Fos-ir in the cPAG than that occurring without physical interaction with pups. Recent studies revealed a contribution to this activation from trigeminal stimuli-necessary for retrieval and licking of pups (Stern and Kolunie, 1989, 1991; Stern, 1996a,b)—but not rooting on the ventrum (Stern et al., 1997); however, the reduced trigeminal contribution to Fos activation in the cPAG (Blomqvist and Craig, 1991) attributable to perioral anesthesia of the dam is compensated by prolonged kyphosis (Stern et al., 1997). Similar to expression of Fos in the medial amygdala or medial preoptic area (mPOA) after sex- or pup-related inputs from olfactory and somatosensory modalities (Baum and Everitt, 1992; Numan and
Numan, 1995), the single elimination of one effective source of tactile contact with the litter, from snout or nipples, does not reduce Fos expression in the $\mathrm{cPAG}_{1, \mathrm{vl}}$ to the low levels seen in dams without physical access to pups.

NSK pup contact elicited the highest levels of Fos in the rPAG, especially dorsolaterally. This may reflect the effects of mPOA excitation during the performance of active maternal behavior (Numan, 1994), because the projection of the mPOA to the rPAG is restricted almost exclusively to its dorsal areas (Rizvi et al., 1992). In support, preliminary findings suggest that prepartum lesions of rPAG results in deficits in retrieval and licking of the pups (J. S. Lonstein, unpublished observations).

\section{Comparison of pre- and postpartum PAG lesions}

The effects of cPAG lesions on kyphosis and maternal aggression were apparent on the first postpartum tests, which occurred at least 6-7 d after prepartum lesioning, but required $2-3 \mathrm{~d}$ to be fully effective after the postpartum lesions. The direction of changes after postpartum lesioning suggests that previous experience with nursing or fighting did not ameliorate its effects. Rather, these differences are likely related to the time course of degenerative changes seen after traumatic brain injury. Significant degeneration of efferent or afferent connections of a lesioned region often requires at least 1 week (Gage et al., 1986; Pallini et al., 1988; Sauer and Oertel, 1994), rendering this explanation unlikely. More probable is that short-term degenerative changes surrounding the lesion occurred within days after surgery, thereby increasing the size as well as the effectiveness of the neural insult (Wolf and DiCara, 1969; Oestreicher et al., 1988; Pschorn et al., 1993). This expansion of apparent lesion size continues through the first 2 weeks after surgery (Wolf and DiCara, 1969), a likely explanation of larger lesions in dams killed 12-14 d after prepartum PAG-x versus only $7 \mathrm{~d}$ after postpartum surgery. 

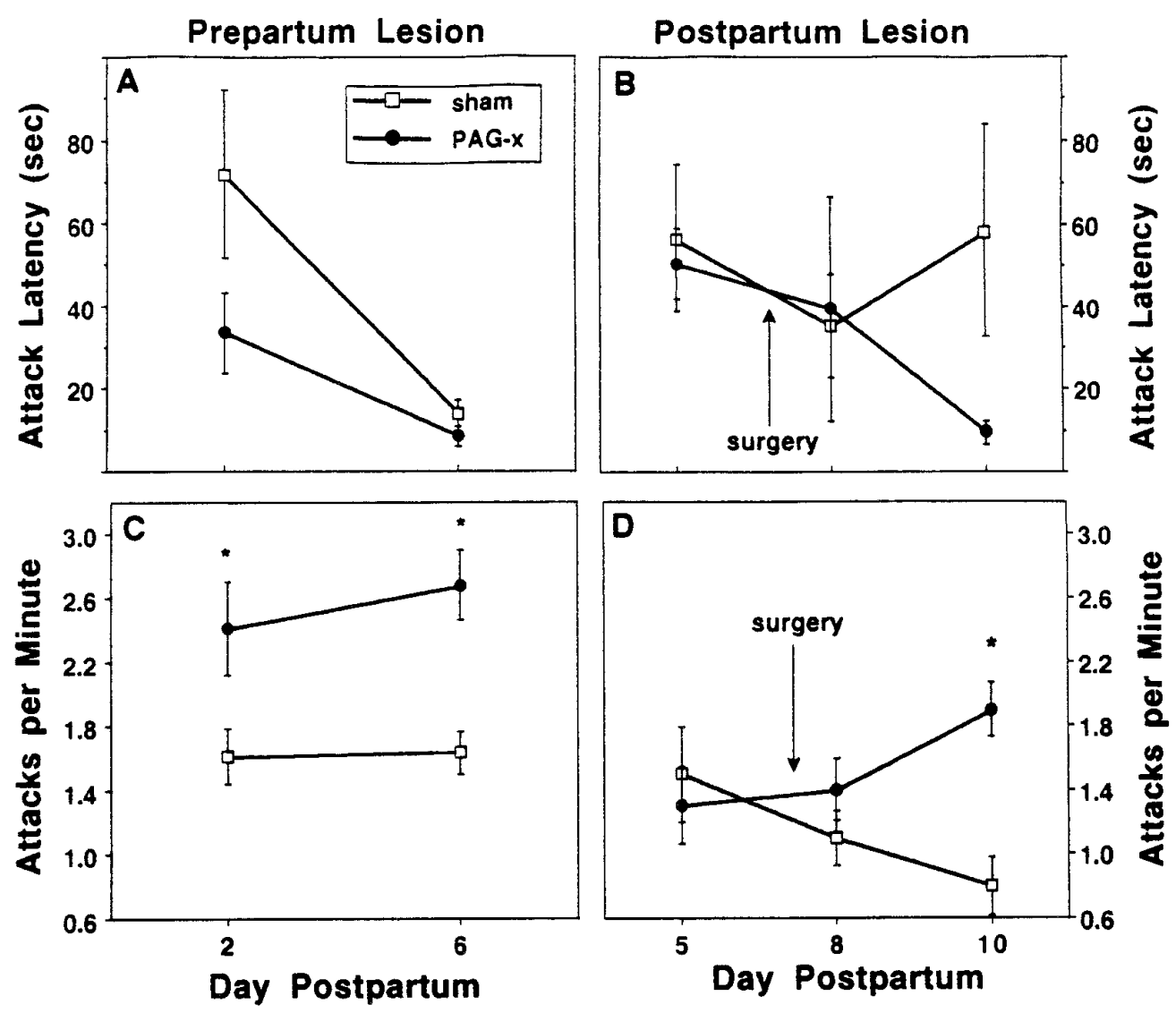

Figure 9. Effects of prepartum (left) or postpartum (right) sham (unfilled squares) or cPAG ( filled circles) lesions on aggressive behaviors (mean \pm SEM) toward a strange male intruder during a $5 \mathrm{~min}$ (left) or $10 \mathrm{~min}$ (right) interaction. $A, B$, Latency to first attack (sec), and $C, D$, attack rate, calculated as the number of attacks per minute between the onset of attacking and the remainder of the test. ${ }^{*} p \leq 0.05$.

cPAG lesions performed either pre- or postpartum produced strikingly similar results, indicating effects on both the onset and maintenance of kyphosis and maternal aggression. In contrast, the integrity of the cPAG is not necessary for active maternal behaviors directed toward pups during either stage. Although the present results cannot definitively exclude a neuroendocrine basis for the reduced litter growth after cPAG lesions, the PAG is not in the known afferent path of suckling-induced prolactin and oxytocin secretion (Tindal, 1978; Wakerley et al., 1994). Rather, our results suggest a functional role for the kyphotic nursing posture. By providing room for movement and breathing, kyphosis likely facilitates the pups' location, attachment, and adherence to a nipple, as well as suckling followed by swallowing during milk letdown (Lorenz, 1992). This facilitation is more important for very young, largely immobile pups, because $\mathrm{cPAG}_{1, \mathrm{vl}}$ lesions performed prepartum resulted in the most pronounced deficits in pup growth in the first postnatal week.

\section{Role of the cPAG in kyphosis}

Afferent fibers from the nipples project to widely overlapping regions of the spinal cord, primarily targeting dorsal horn laminae I and II (Tasker et al., 1986). Neurophysiological inputs from suckling necessary for both neuroendocrine secretions controlled by the hypothalamus and kyphosis are transmitted in the spinal dorsolateral columns (Fukuoka et al., 1984; DuBois-Dauphin et al., 1985a; Stern et al., 1993). This information diverges before or within the midbrain, because lesions of the PP nucleus disrupt suckling-induced oxytocin release but not kyphosis (Hansen and Köhler, 1984; DuBoisDauphin et al., 1985b; Hansen and Ferreira, 1986a; Factor et al., 1993). The spinomesencephalic tract transmits impulses from dorsal horn lamina I through the ascending dorsolateral columns of the spinal cord to synapse onto the $\mathrm{CPAG}_{1, \mathrm{vl}}$, particularly at intercollicular levels (Swett et al., 1985; Yezierski, 1988), thereby possibly transmitting afferents from suckling as well as other somatosensory stimuli (Yezierski and Schwartz, 1986).

Because suckling-induced nursing behavior in rats is necessarily accompanied by inhibition of motorically active behaviors such as retrieval and licking of pups (Voloschin and Tramezzani, 1979; Stern and Johnson, 1990), the PAG may play a second role in maternal behavior by inhibiting the MPOA, a forebrain site critical for retrieval and nestbuilding (Numan, 1994). Indeed, there are dense reciprocal connections between the mPOA and the $\mathrm{cPAG}_{1, \mathrm{vl}}$ (Simerly and Swanson, 1986, 1988; Rizvi et al., 1992), and neuronal activity in the mPOA is inhibited after stimulation of the ventral PAG (MacLeod and Mayer, 1980). The $\mathrm{CPAG}_{1, \mathrm{v} \text { l, }}$, however, does not fully control suckling-induced inactivity, because dams with lesions in this site eventually became quiescent while nursing in another posture; therefore, larger lesions than the very discrete ones imposed in the present studies may be needed to prevent suckling-induced inhibition of movement. Similarly, elimination of lactation requires large lesions in the mesencephalic tegmentum far lateral to the PAG (Tindal, 1978; DuboisDauphin et al., 1985b; Wakerley et al., 1994). 


\section{Maternal aggression and the PAG}

The integrity of the PAG is essential to the display of defensive behavior in cats and rats (Bandler and Depaulis, 1991; Depaulis et al., 1992). Although important forebrain inputs from the amygdala and ventromedial hypothalamus to the PAG contribute to the expression of aggressive rage in cats (Siegel and Brutus, 1990), the role of the PAG in aggression elicited by hypothalamic stimulation has not been as well defined in rats (Mos et al., 1983; Roberts and Nagel, 1996). With respect to maternal aggression in lactating rats, three excitatory regions have been identified: PP nucleus and two of its projection sites, amygdala and ventromedial hypothalamus (Hansen and Ferreira, 1986b; Hansen, 1989; Factor et al., 1993). Furthermore, maternal aggression in rats may require ventral trunk stimulation for its maintenance, because it is greatly reduced by lesions of the PP, part of the ascending milkejection pathway (Hansen and Köhler, 1984; Hansen and Ferreira, 1986a), by several hours of separation from the litter, or by anesthetization of the nipples and surrounding tissue (Stern and Kolunie, 1993). Hence, our finding that a small lesion in the cPAG, one that disrupts a SK-induced behavioral alteration (kyphosis), heightens maternal aggression was unexpected.

The PAG also modulates fear-motivated behavior (Fanselow, 1991), and reduced fearfulness during lactation (Fleming and Luebke, 1981) is correlated with increased postpartum aggression (Hård and Hansen, 1985; Hansen and Ferreira, 1986a). Heightened aggression by PAG-x dams in the present study was characterized by a tendency to attack more quickly, decreased aggressive grooming, and a more rapid pacing of attacks, all suggestive of a reduced threshold to attack, consistent with an interpretation of decreased fearfulness. Indeed, our recent finding of a further decrease in the lactating rat's fearfulness in an elevated plus-maze (Pellow et al., 1985) after lesioning of the $\mathrm{CPAG}_{1, \mathrm{vl}}$ (Lonstein et al., 1997) provides experimental support for the proposed link between reduced fear and intensified aggression. Apparently, neuronal activity in the $\mathrm{CPAG}_{1, \mathrm{vl}}$ tempers maternal aggression, and possibly other aggressive behavior, in rats.

\section{REFERENCES}

Bandler R, Depaulis A (1991) Midbrain periaqueductal gray control of defensive behavior in the cat and the rat. In: The midbrain periaqueductal gray matter: functional, anatomical, and neurochemical organization (Depaulis A, Bandler R, eds), pp 175-198. New York: Plenum.

Bandler R, Carrive P, Depaulis A (1991) Introduction: emerging principles of organization of the midbrain periaqueductal gray matter. Op. cit. pp 1-8.

Basbaum AI, Fields HL (1984) Endogenous pain control systems, brainstem spinal pathways and endorphin circuitry. Annu Rev Neurosci 7:309-338.

Baum MJ, Everitt BJ (1992) Increased expression of c-fos in the medial preoptic area after mating in male rats: role of afferent inputs from the medial amygdala and midbrain central tegmental field. Neuroscience 50:627-646.

Blomqvist AJ, Craig AD (1991) Organization of spinal and trigeminal input to the PAG. In: The midbrain periaqueductal gray matter: functional, anatomical, and neurochemical organization (Depaulis A, Bandler R, eds), pp 345-363. New York: Plenum.

Borofsky AL, Taylor J, Massari VJ (1983) Dorsal raphe-hypothalamic projections provide the stimulatory serotonergic input to sucklinginduced prolactin release. Endocrinology 113:1894-1903.

Bridges RS (1996) Biochemical basis of parental behavior in the rat. In: Parental care: evolution, mechanisms, and adaptive significance. Advances in the study of behavior, Vol 25 (Rosenblatt JS, Snowden CT, eds), pp 215-242. New York: Academic.

Cameron AA, Khan IA, Westlund KN, Willis WD (1995b) The efferent projections of the periaqueductal gray in the rat: a Phaseolus vulgarisleucoagglutinin study. II. Descending projections. J Comp Neurol 351:585-601.
Depaulis A, Keay K, Bandler K (1992) Longitudinal neuronal organization of defensive reaction in the midbrain periaqueductal gray regions of the rat. Exp Brain Res 90:307-318.

Drewett RF, Statham C, Wakerley JB (1974) A quantitative analysis of the feeding behavior of suckling rats. Anim Behav 22:907-913.

DuBois-Dauphin M, Armstrong WE, Tribollet E, Driefuss JJ (1985a) Somatosensory systems and the milk-ejection reflex in the rat. II. The effects of lesions in the ventroposterior thalamic complex, dorsal columns and lateral cervical nucleus-dorsolateral funiculus. Neuroscience 15:1131-1140.

DuBois-Dauphin M, Armstrong WE, Tribollet E, Dreifuss JJ (1985b) Somatosensory systems and the milk-ejection reflex in the rat. I. Lesions of the mesencephalic lateral tegmentum disrupt the reflex and damage mesencephalic somatosensory connections. Neuroscience 15: 1111-1129.

Factor EM, Mayer AD, Rosenblatt JS (1993) Peripeduncular nucleus lesions in the rat: I. Effects on maternal aggression, lactation, and maternal behavior during pre- and postpartum periods. Behav Neurosci 107:166-185.

Fanselow MS (1991) The midbrain periaqueductal gray as a coordinator of action in response to fear and anxiety. In: The midbrain periaqueductal gray matter: functional, anatomical, and neurochemical organization (Depaulis A, Bandler R, eds), pp. 151-173. New York: Plenum.

Fénelon VS, Poulain DA (1992) Electrical activity of dorsal horn neurons during the suckling-induced milk ejection reflex in the lactating rat. J Neuroendocrinol 4:575-584.

Fénelon VS, Poulain DA, Theodosis DT (1993) Oxytocin neuron activation and Fos expression: a quantitative analysis of the effect of lactation, parturition, osmotic and cardiovascular stimulation. Neuroscience 53:77-89.

Fleming AS, Luebke C (1981) Timidity prevents the virgin female rats from being a good mother: emotionality differences between nulliparous and parturient females. Physiol Behav 27:863-870.

Fukuoka T, Negoro H, Honda K, Higuchi T, Nishida E (1984) Spinal pathway of the milk-ejection reflex. Biol Reprod 30:74-81.

Gage FH, Wictorin K, Fischer W, Williams LR, Varon S, Bjorklund A (1986) Retrograde cell changes in medial septum and diagonal band following fimbria-fornix transection: quantitative temporal analysis. Neuroscience 19:241-255.

Hansen S (1989) Medial hypothalamus involvement in maternal aggression in rats. Behav Neurosci 100:1035-1046.

Hansen S, Ferreira A (1986a) Food intake, aggression, and fear behavior in the mother rat: control by neural systems concerned with milk ejection and maternal behavior. Behav Neurosci 103:64-70.

Hansen S, Ferreira A (1986b) Effects of bicuculline infusions in the ventromedial hypothalamus and amygdaloid complex on food intake and affective behavior in mother rats. Behav Neurosci 100:410-415.

Hansen S, Köhler C (1984) The importance of the peripeduncular nucleus in the neuroendocrine control of sexual behavior and milk ejection in the rat. Neuroendocrinology 39:563-572.

Hård E, Hansen S (1985) Reduced fearfulness in the lactating rat. Physiol Behav 35:641-643.

Heeb MM, Yahr P (1996) C-fos immunoreactivity in the sexually dimorphic area of the hypothalamus and related brain regions of male gerbils after exposure to sex-related stimuli or performance of specific sexual behaviors. Neuroscience 72:1049-1071.

Hennessey AC, Camak L, Gordon F, Edwards DA (1990) Connections between the pontine central gray and the ventromedial hypothalamus are essential for lordosis in female rats. Behav Neurosci 104:477-488.

Holstege G (1989) An anatomical study on the final common pathway for vocalization in the cat. J Comp Neurol 284:242-252.

Lonstein JS, Swann JM, Stern JM (1995) C-fos expression in the brain of lactating Long-Evans rats after mother-young interaction with or without suckling. Soc Neurosci Abstr 21:465.

Lonstein JS, Simmons DA, Stern JM (1997) Effects of periaqueductal gray lesions on nursing, aggressive, fear, and sexual behaviors in lactating rats. Dev Psychobiol Abstr, in press.

Lorenz DN (1992) Suckling physiology and behavior of rats: an integrated theory of ingestion and satiety. In: Progress in psychobiology and physiological psychology, Vol 15 (Epstein AN, Morrison AR, eds), pp 1-83. New York: Academic.

Lucion AB, de Almeida RMM (1996) On the dual nature of maternal aggression in rats. Aggressive Beh 22:365-373.

MacLeod NK, Mayer ML (1980) Electrophysiological analysis of path- 
ways connecting the medial preoptic area with the mesencephalic central gray matter in rats. J Physiol (Lond) 298:53-70.

Mantyh PW, Pechanski M (1982) Spinal projections from the periaqueductal grey and dorsal raphe in the rat, cat and monkey. Neuroscience 7:2769-2776.

Morgan JI, Curran T (1991) Stimulus-transcription coupling in the nervous system: involvement of the inducible proto-oncogenes Fos and Jun. Annu Rev Neurosci 14:421-451.

Mos J, Lammers JHCM, van der Poel AM, Bermond B, Meelis W, Kruk MR (1983) Effects of midbrain central gray lesions on spontaneous and electrically induced aggression in the rat. Aggressive Beh 9:133-155.

Mouton LJ, Holstege G (1994) The periaqueductal gray in the cat projects to lamina VIII and the medial part of lamina VII throughout the length of the spinal cord. Exp Brain Res 101:253-264.

Numan M (1994) Maternal behavior. In: The physiology of reproduction, 2nd Ed (Knobil E, Neill JD, eds), pp 221-302. New York: Raven.

Numan M, Callahan EC (1980) The connections of the medial preoptic region and maternal behavior in the rat. Physiol Behav 25:653-665.

Numan M, Numan MJ (1995) Importance of pup-related sensory inputs and maternal performance for the expression of Fos-like immunoreactivity in the preoptic area and ventral bed nucleus of the stria terminalis of postpartum rats. Behav Neurosci 109:135-149.

Oestreicher AB, Devay P, Isaacson RL, Gispen WH (1988) Changes in the distribution of the neuron-specific B-50, neurofilament protein and glial fibrillary acidic proteins following an unilateral mesencephalic lesion in the rat. Brain Res Bull 21:713-722.

Pallini R, Fernandez E, Sbricolli A (1988) Retrograde degeneration of corticospinal axons following transection of the spinal cord in rats. J Neurosurg 68:124-128.

Paxinos G, Watson C (1986) The rat brain in stereotaxic coordinates. New York: Academic.

Pellow S, Chopin P, File SE, Briley M (1985) Validation of open:closed arm entries in an elevated plus-maze as a measure of anxiety in the rat. J Neurosci Methods 14:149-167.

Pfaff DW, Modianos D (1985) Neural mechanisms of female reproductive behavior. In: Handbook of behavioral neurobiology, Vol 7: reproduction (Adler N, Pfaff DW, Goy RW, eds), pp 423-493. New York: Plenum.

Pfaff DW, Schwartz-Giblin S, McCarthy MM, Kow LM (1994) Cellular mechanisms of female reproductive behaviors. In: The physiology of reproduction, 2nd Ed (Knobil E, Neill JD, eds), pp 107-220. New York: Raven.

Pschorn U, Korperich H, Heymans L, Subramanian S, Kuhn W (1993) MRI and MRS studies on the time course of rat brain lesions and the effect of drug treatment: volume quantification and characterization of tissue heterogeneity by parameter selection. Magn Reson Med 30:174-182.

Rizvi TA, Ennis M, Shipley MT (1992) Reciprocal connections between the medial preoptic area and the midbrain periaqueductal gray in rat: a WGA-HRP and PHA-L study. J Comp Neurol 315:1-15.

Roberts WW, Nagel J (1996) First-order projections activated by stimulation of hypothalamic sites eliciting attack and flight in rats. Behav Neurosci 110:509-527.

Sakuma Y, Pfaff DW (1979a) Facilitation of female reproductive behavior from mesencephalic central gray in the rat. Am J Physiol 237:R278-284.

Sakuma Y, Pfaff DW (1979b) Mesencephalic mechanisms for integration of female reproductive behavior in the rat. Am J Physiol 237:R285-290.

Sauer H, Oertel WH (1994) Progressive degeneration of nigrostriatal dopamine neurons following intrastriatal terminal lesions with 6-hydroxydopamine: a combined retrograde tracing and immunocytochemical study in the rat. Neuroscience 59:401-415.

Siegel A, Brutus M (1990) Neurosubstrates of aggression and rage in the cat. In: Progress in psychobiology and physiological psychology (Epstein AN, Morrison AR, eds), pp 135-233. San Diego: Academic.

Simerly RB, Swanson LW (1986) The organization of neural inputs to the medial preoptic nucleus of the rat. J Comp Neurol 246:312-342.

Simerly RB, Swanson LW (1988) Projections of the medial preoptic nucleus: a Phaseolus vulgaris leucoagglutinin anterograde tract-tracing study in the rat. J Comp Neurol 270:209-242.

Stern JM (1989) Maternal behavior: sensory, hormonal and neural determinants. In: Psychoendocrinology (Brush FR, Levine S, eds), pp 103-226. San Diego: Academic.
Stern JM (1990) Multisensory regulation of maternal behavior and masculine sexual behavior: a revised view. Neurosci Biobehav Rev 14:183-200.

Stern JM (1996a) Somatosensation and maternal care in Norway rats. In: Parental care: evolution, mechanisms, and adaptive significance. Advances in the study of behavior, Vol 25 (Rosenblatt JS, Snowden CT, eds), pp 243-294. San Diego: Academic.

Stern JM (1996b) Trigeminal lesions and maternal behavior in Norway rats: II. Disruption of parturition. Physiol Behav 60:187-190.

Stern JM, Johnson SK (1990) Ventral somatosensory determinants of nursing behavior in Norway rats: I. Effects of variations in the quality and quantity of pup stimuli. Physiol Behav 47:993-1011.

Stern JM, Kolunie JM (1989) Perioral anesthesia disrupts maternal behavior during early lactation in Long-Evans rats. Behav Neural Biol 52:20-38.

Stern JM, Kolunie JM (1991) Trigeminal lesions and maternal behavior in rats. I. Effects of cutaneous rostral snout denervation on maintenance of nuturance and maternal aggression. Behav Neurosci 105:984-997.

Stern JM, Kolunie JM (1993) Maternal aggression of rats is impaired by cutaneous anesthesia of ventral trunk, but not by nipple removal. Physiol Behav 54:861-868.

Stern JM, Levine S (1972) Pituitary-adrenal activity in the post-partum rat in the absence of suckling stimulation. Horm Behav 3:237-246.

Stern JM, Lonstein JS (1996) Nursing behavior is impaired in a small nestbox and with hyperthermic pups. Dev Psychobiol 29:101-122.

Stern JM, Dix L, Bellomo C, Thramann C (1992) Ventral trunk somatosensory determinants of nursing behavior in Norway rats. II. Role of nipple and surrounding sensations. Psychobiology 20:71-80.

Stern JM, Yu Y-L, Crockett DC (1993) Spinal pathway mediating suckling-induced nursing behavior and neuroendocrine reflexes. Soc Neurosci Abstr 19:1610.

Stern JM, Lonstein JS, Simmons DA (1997) Suckling stimulation, but not pup rooting or perioral inputs, elevates Fos activity in a specific region of the midbrain periaqueductal gray of lactating rats. Dev Psychobiol Abstr, in press.

Swett JE, McMahon SB, Wall PD (1985) Long ascending projections to the midbrain from cells of lamina I and nucleus of the dorsolateral funiculus of the rat spinal cord. J Comp Neurol 238:401-416.

Tasker JG, Theodosis DT, Poulain DA (1986) Afferent projections from the mammary glands to the spinal cord in the lactating rat. I. A neuroanatomical study using the transganglionic transport of horseradish peroxidase-wheatgerm agglutinin. Neuroscience 19:495-509.

Tindal JS (1978) Control of prolactin secretion. In: The endocrine hypothalamus (Jeffcoate SL, Hutchinson JSM, eds), pp 333-361. New York: Academic.

Van Bockstaele EJ, Aston-Jones G, Pieribone VA, Ennis M, Shipley MT (1991) Subregions of the periaqueductal gray topographically innervate the rostral ventral medulla in the rat. J Comp Neurol 309:305-327.

Van Erp AMM, Druk MR, Meelis W, Veening JG (1993) Periaqueductal gray lesions do not affect grooming, induced electrically in the hypothalamic paraventricular area in the rat. Behav Brain Res 59:95-101.

Voloschin LM, Tramezzani JH (1979) Milk ejection reflex linked to slow wave sleep in nursing rats. Endocrinology 105:1201-1207.

Wakerley JB, Clarke G, Summerlee AJS (1994) Milk ejection and its control. In: The physiology of reproduction, Vol 2, 2nd Ed (Knobil E, Neill JD, eds), pp 1131-1178. New York: Raven.

Waldbillig RJ (1975) Attack, eating, drinking and gnawing elicited by electrical stimulation of rat mesencephalon and pons. J Comp Physiol Psychol 89:200-212.

Wolf G, DiCara LV (1969) Progressive morphologic changes in electrolytic brain lesions. Exp Neurol 23:529-536.

Yezierski RP (1988) Spinomesencephalic tract: projections from the lumbosacral spinal cord of the rat, cat, and monkey. J Comp Neurol 267:131-146.

Yezierski RP (1991) Somatosensory input to the periaqueductal gray: a spinal relay to a descending control center. In: The midbrain periaqueductal gray matter: functional, anatomical, and neurochemical organization (Depaulis A, Bandler R, eds), pp 365-386. New York: Plenum.

Yezierski RP, Schwartz RH (1986) Response and receptive-field properties of spinomesencephalic tract cells in the cat. J Neurophysiol 55: 76-96. 